Consequences of Discretion in the Formation of Commodities Policy

John McLaren, Columbia University

March 1995

Discussion Paper Series No. 721 


\title{
Consequences of Discretion in the Formation of Commodities Policy
}

\author{
John McLaren \\ Department of Economics \\ Columbia University \\ New York, New York, 10027
}

March 1995

I am grateful to seminar participants at Columbia and Dartmouth, and to Joshua Aizenman, Bill Lehr, Andy Newman, and Sylvia Weyerbrock for helpful comments. All errors are mine. 


\begin{abstract}
.
We present a simple model of endogenous commodity policy, in which (i) government action is affected by the size of private inventories, and (ii) private inventories are determined by speculators trying to forecast government action. The interaction between these two forces is rich, giving rise to the possibility of bubbles and extrinsic volatility in a market which in the absence of government would have had a unique, well-behaved, equilibrium. In addition, under some conditions a government that wishes to support the price but is unable to commit to future action may be impotent; and a government that does not want to support the price may be "trapped" into doing so anyway by the activity of speculators.
\end{abstract}




\section{Introduction.}

The presence of government in many commodity markets is so ubiquitous and heavy handed that it is impossible to understand the behaviour of those markets without giving some thought to commodity policy'. As a result, the positive economics of commodity markets has long made a lot of room for policy, in two principal ways. First, there is a strain of literature that analyzes rational expectations equilibrium in commodity markets with an exogenous policy rule imposed ${ }^{2}$. In this approach, causation runs from policy to market behaviour. Second, there is a strain which attempts to explain commodity policies as the product of optimizing government behaviour ${ }^{3}$. In this approach, causation runs from market conditions to policy.

Here, we claim that these separate literatures, by remaining separate, have missed something important. Specifically, this paper tries to untangle the mutual effects of private agents' behaviour and policy in commodity markets when policy is endogenous. The point

The heavy hand of policy in domestic agricultural commodity markets is well known. See Johnson (1973) and Gardner (1992) for surveys. International commodity markets have also been heavily regulated through buffer stocks, export quotas, subsidies, acreage controls, and other instruments. For useful histories see Nappi (1979) and Finlayson and Zacher (1988), and for a review see Gilbert (1987).

${ }^{2}$ Some pioneering contributions are Salant (1983) and Wright and Williams (1984). For an application to the soybean market, see Miranda and Helmberger (1988). For a survey, see Williams and Wright (1991, Chapters 13 and 14). All of these studies posit an exogenous policy rule; given that rule, the implementing authority responds in the prescribed way to the market from day to day, but there is no consideration given to how the rule is established.

${ }^{3}$ See Gardner (1987) and Babcock, Carter and Schmitz (1990) for efforts focused on US farm price supports. See Gardner $(1983,1992)$ for a unified theoretical treatment and a survey, respectively. This can be thought of as a special case of the general theory of regulation outlined by Peltzman (1976). 
made here is that the interaction between government discretion and private speculation can dramatically change the nature of equilibrium in the market for a storable primary commodity, and can indeed make the outcome indeterminate.

More specifically, a simple nonstochastic model is presented in which there is a unique (trivial) equilibrium if there is no government. When a rational, optimizing government is added, multiple equilibria and extrinsic volatility can result. Among the range of outcomes thus made possible, welfare differences are large.

The mechanism through which these phenomena arise is the effect of private inventories on the government's incentives to intervene in the market. In this model, the government would always have some interest in price supports for political reasons and because of national monopoly power, but the benefits from the policy may not be worth its cost. In general, the net gain from price supports may be affected either positively or negatively by the level of private inventories. In the former case multiple equilibria may result, and in the latter case extrinsic volatility may result. Briefly, if the net gain from price supports is increasing in private inventories, a surge in speculative enthusiasm fueling speculative demand can create the large inventories needed for a policy of price supports to be politically justified. In that case, the speculative enthusiasm indeed leads to price supports and thus higher prices, and is self-fulfilling. By contrast, if the net gain from supports is decreasing in private inventories, it may be that no expectations can be fulfilled in a nonrandom equilibrium; bullish expectations lead to high stocks and no price supports, hence low prices, and bearish expectations lead to low stocks and active supports, hence high prices. The only equilibrium is random. The paper makes an attempt to sort out when these various 
outcomes are most likely ${ }^{4}$.

In addition, the interaction between speculation and government discretion can lead to situations in which the government wishes to initiate price supports, but cannot because of speculative pessimism; and cases in which the government does not want supports but is "trapped" into establishing them anyway by speculative enthusiasm. In the latter case, which always involves a large welfare loss, it is speculative hoarding that backs the government into a corner. Thus, the presence of government and its inability to commit result in a possibility of socially destructive hoarding that would be impossible in the absence of government.

This analysis can be applied to any market with a storable commodity in which some government has an incentive to try to support the price. Thus, U.S. and EC farm policy fit the setting of the model, as do withholding policies often employed by exporting countries with market power. Examples of these latter include the valorization policy followed by prewar Brazil ${ }^{5}$ and schemes implemented by consortia of exporting countries, such as with coffee at the moment and tin in the early $1930^{\prime} \mathrm{s}^{6}$. These all have in common a government

4 A similar logic could be applied to the planting of a perennial crop with sunk costs and delayed output; as with speculators, the planters need to forecast future government policy in deciding whether or not to plant, and at the same time their collective decisions largely determine government policy. Throughout, although the discussion will be entirely about speculative behaviour, it will be well to keep in mind an extension to planter behaviour.

${ }^{5}$ This was a policy of government purchase for storage or destruction in order to raise the world price; at the time Brazil supplied a majority of world consumption. See Krasner (1973).

${ }^{6}$ See Fox (1971, pp. 151-4). 
intervening to raise the price ${ }^{7}$ of the commodity in order to help producers, at the expense of taxpayers and consumers. The case of International Commodity Agreements (ICA's), negotiated under United Nations auspices with producer and consumer country participation, is similar in practice because often there is an explicit element of transfer from consumers to producers in the arrangement, which the consumer country governments accept as a form of foreign aid ${ }^{8}$. Thus, once again, the object is often to raise the price. In these sorts of markets, speculation is usually very active, with much speculative attention applied to forecasting government action"; and government behaviour is much affected by private inventories $^{10}$. Those elements are the key to the model.

This model is also related to the theory of "hoarding"; price destabilizing speculation;

${ }^{7}$ Strictly speaking, we should distinguish between policies that raise the world price and the domestic price (as U.S. farm policies before the mid-1980's; see Carr, et. al (1988)) and those that raise the domestic price but lower the world price (as is likely the case with current U.S. and E.C. policies; see Babcock, et. al., (1990)). The model in this paper, taken literally, fits the former class but not the latter. However, the difference is only in the details of the mechanics; much of the reasoning used here would apply to the second class of policies mutatis mutandis.

${ }^{8}$ See Nappi $(1979$, p. 61). For a particularly clear indication of this in the case of the Coffee Agreement, see Short (1987), and Fisher (1972).

${ }^{9}$ Examples abound of sharp price movements following news relevant purely to future policy. For example, on Monday, March 30, 1992, New York near-term futures prices for coffee fell by $3.2 \%$ on news that the Brazilian Foreign Minister had resigned. See New York Times, Tues, March 31, 1992, p. D18. For other examples, see: New York Times 3/5/1992, p. D19;3/6/1992, p. D13; 3/7/1992, p. 48; and 5/3/1991, p. D15. Wheat and, of course, oil, provide many similar examples.

${ }^{10}$ For example, large private stocks overhanging the market had an important role in the creation of new US grain price supports in January 1972. See Halow (1989, Chapter 5) for an account. They were also important in the formation of the first International Coffee Agreement. See Fisher (1972, p. 9). By contrast, the absence of large cocoa stocks has been cited as a reason the International Cocoa Agreement talks failed during the same period (Short, 1987, p. 293). 
the theory of asset price bubbles; and the theory of time-consistency in policy making. (i) In some of the equilibria in this model, private agents cause a welfare loss by storing too much. That is, "hoarding" occurs. Wright and Williams (1984) find a numerical example of a similar result in a model with an exogenously imposed price ceiling; the point there is that the price ceiling distorts incentives in such a way as to make it too attractive to store in scarcity and too unattractive in gluts. The question, approach and finding in this paper are different; here, hoarding is harmful because it can induce an endogenous distortionary policy.

(ii) Hart and Kreps (1986) showed that there is in general no reason for the presumption that rational speculation will have a stabilizing effect on commodity prices. The particular model they offered involved rational responses to noisy signals of future market conditions. One contribution of the present paper is to offer a very different angle on the question of price destabilizing speculation. In some regions of the parameter space for this model, speculation is destabilizing in the sense that the only equilibrium which clears the speculative market is random, even though the model is inherently nonrandom. However, this is true only in the presence of government; the existence of the public sector as a strategic player is what makes speculation destabilizing.

(iii) When there are multiple equilibria in this model, one of the equilibria is laissez faire, and there is a sense in which the other one constitutes a bubble. This is not meant in quite the usual sense of the word in financial theory, in which the price of an asset differs from the (risk corrected) expected present value of a dividend stream, but rather in the sense that the price of the commodity can become artificially inflated above its laissez faire equilibrium level by a burst of spontaneous, self-fulfilling speculative enthusiasm. However, 
this form of bubble is different in an extreme way from all asset bubbles in the literature, as demonstrated by the fact that it can be generated in a two-period model. Conventional theories of asset bubbles require an infinite horizon of possibility, even if the bubble itself has a finite lifetime (as in Blanchard, 1979). This has led to many logical difficulties for rational bubbles as an equilibrium phenomenon (Diba and Grossman, 1988). However, none of that is an issue here, because the mechanism is so very different: Instead of working purely through traders' expectations, here, bubbles arise because speculative behaviour changes government's incentives ${ }^{11}$. In that regard, the present model is closest in spirit to the Obstfeld (1986) model of exchange rate crises. However, here the setting and mechanisms are all very different, and we hypothesize an optimizing government ${ }^{12}$.

(iv) This paper adds to the literature on time consistent policy begun by Kydland and Prescott (1977) the observation that a lack of commitment can lead not only to the implementation of the wrong policy and a suboptimal outcome, but that it can actually lead the outcome to be indeterminate, and can lead to randomization.

Section 2 lays out the model, Section 3 the discretionary equilibrium, Section 4 the optimum under full commitment and comparison with the discretionary equilibrium, and

\footnotetext{
${ }^{11}$ Most theories of bubbles need an infinite chain of agents, each willing to buy at the inflated price because it knows it can sell again at an inflated price. Here, that infinite chain is broken: In the high price equilibrium, the government stands ready to buy at an inflated price because of politics. It does not necessarily need to expect to resell.

${ }^{12}$ Variants of this argument are also made in McLaren (1992), where it is shown that various kinds of exogenous commodity policy rules can make speculative bubbles possible, and (1993), where it is shown that under some conditions the need for a buffer stock manager to maintain a reputation with traders can lead to sunspot equilibria in an otherwise wellbehaved market.
} 
Section 5 discusses the implications of relaxing some key assumptions. Section 6 offers concluding remarks.

\section{The model.}

Consider a country, "Home", which produces and exports a storable commodity. We need to concern ourselves with four classes of agent. First, the producers of the commodity all are citizens of Home. They reap a harvest of $h$ each period, where $h>0$ is a constant, and have no production costs. They can not store the commodity. Second, consumers all are foreigners, and have per-period inverse demand given by:

$$
\begin{aligned}
\mathrm{P}(\mathrm{Q}) & =\beta(\overline{\mathrm{Q}}-\mathrm{Q})^{\alpha} \text { if } \mathrm{Q}<\overline{\mathrm{Q}} \\
& =0 \text { if } \mathrm{Q}>\mathrm{Q}
\end{aligned}
$$

where $\mathrm{Q}$ is world consumption, $\overline{\mathrm{Q}}>\mathrm{h}$ is the satiation point, and $\beta, \alpha>0$. Third, speculators all are foreigners and can costlessly store any amount of the commodity without depreciation from one period to the next. Each speculator seeks to maximize her expected capital gains. All three of these classes of agent take price as given.

The fourth class of agent is government. We will ignore all foreign governments in what follows. The Home government has two policy instruments available: poll taxes and open market purchases of the commodity. The government is concerned with the well-being of its taxpayers at large and also of the producers of the commodity. We allow for the possibility that the producers are politically favored compared with other taxpayers. Thus, the 
government maximizes the present value of domestic welfare, which in a given period is measured by:

$$
P(Q) \theta h-C(B)
$$

where $B$ is net government purchases of the commodity in that period, $C(B)$ is the fiscal cost of the price support policy, and $\theta \geq 1$ is a parameter measuring the political clout of the producers $^{13}$. The cost is given by:

$$
\begin{aligned}
C(B) & =0 \text { if } B=0 \\
& =P(Q) B+K \text { if } B>0,
\end{aligned}
$$

where $\mathrm{K}>0$ is a fixed cost of administration required to have any active market intervention. This should be thought of as comprising the costs of hiring an administrator and staff, providing for offices and overhead, and perhaps building warehouse space ${ }^{14}$. It could also be thought of as including the political resources required to get a farm bill through Congress, which would have an opportunity cost in terms of other legislation that will receive less attention than it otherwise would. If $\theta=1$, the government has a terms of trade motive for purchasing some of the commodity and thus increasing its price. If $\theta>1$, it has an additional

\footnotetext{
${ }^{13}$ This approach can be extended quite mechanically to the analysis of an ICA. We would need to write down the objective functions of the consumer and producer country governments; the former would include a term for the income of foreign producers, to represent the foreign aid motive of consumer participation in the ICA. The actual policy enacted would then be the outcome of a bargaining process. This would differ from the model presented here in details only.

${ }^{14}$ Administrative costs can be significant. A recent estimate put administrative costs of US farm programs at $\$ 600$ million per year. Gardner (1992, p. 85).
} 
redistributive motive for doing so.

All agents have a discount rate of zero. There are two periods. At the beginning of period 1, speculators have an inherited stock of the commodity given by $S \geq 0$. During that period, they must form a forecast for the next period price and decide how much to store. Inventories carried at the end of period 1 are denoted $I \geq 0$. In period 2 , speculators sell their stocks (since with the world ending there is no reason to keep them), and government purchases an amount $\mathrm{B} \geq 0$ (the government has no stocks to begin with). Note that with no period 3, there is no meaningful distinction in period 2 between purchasing to store and purchasing to destroy ${ }^{15}$. With these assumptions, world consumption equals $(\mathrm{S}+\mathrm{h}-\mathrm{I})$ in period 1 and $(\mathrm{I}+\mathrm{h}-\mathrm{B})$ in period 2.

There are two policy regimes of interest. Most of what follows will focus on the case in which the government cannot commit itself in advance to a value for B: the discretionary equilibrium. In this case, government chooses $\mathrm{B}$ in period 2 to maximize welfare given I; understanding this, speculators in period 1 attempt to forecast the period 2 price and their collective behaviour determines I. We will compare this with the regime in which government can commit itself to $B$ at the beginning of period 1 . In both cases, the market must clear at each moment, and that means that consumers must be on their demand curve and expected capital gains from storage must equal zero. This implies that the price and

\footnotetext{
${ }^{15}$ This could also (equivalently) be interpreted as a policy in which the government pays farmers the market price not to harvest some portion of the crop already planted, which is approximately what the US government did with grain farmers in 1972. See Halow (1989, Chapter 5).
} 
hence world consumption of the commodity must be equal in the two periods ${ }^{16}$. This gives us the market clearing condition:

$$
I=(S+B) / 2
$$

Thus, in the absence of government, the equilibrium would be unique and trivial: $\mathbf{I}=\mathbf{S} / 2$; consumption in each period equals $h+S / 2$; price in each period equals $P(h+S / 2)$. This, of course, maximizes (unweighted) world welfare.

Every characteristic of equilibrium that follows is unchanged if we multiply $\beta$ and $\mathrm{K}$ by a common factor, so henceforth we assume without loss of generality that $\beta=1$. We also assume that $\alpha<1$, so that the demand curve is concave, because it makes much of the analysis easier, although it will be clear that much of what follows will also hold for values of $\alpha$ above 1 . The role of concavity will be discussed in later sections. Finally, we make the following assumption on demand:

Assumption 1. Demand is brisk; precisely, $\overline{\mathrm{Q}}>(1+\alpha \theta) \mathrm{h}$.

This simply avoids some annoying taxonomy.

\footnotetext{
${ }^{16} \mathrm{~A}$ period 2 price strictly below the period 1 price together with $\mathrm{I}=0$ would also be consistent with market clearing but would be impossible in this model because $\mathrm{S} \geq 0$ and $\mathrm{B} \geq 0$.
} 


\section{The Discretionary Equilibrium.}

3. A. Period 2: The Government's Decision.

Taking $I$ as given, government in period 2 chooses $B \geq 0$ to maximize:

$$
\mathrm{W}(\mathrm{B}, \mathrm{I})-\phi(\mathrm{B}) \mathrm{K}
$$

subject to $B \in[0, I+h]$, where $\phi(0)=0$ and $\phi(B)=1$ if $B>0$, and:

$$
W(B, I)=P(I+h-B)[\theta h-B] .
$$

Assume for the moment that a price support program is established, so that $\mathrm{B}>0$. Then the net marginal benefit to procurement is:

$$
W_{B}(B, I) \quad=-P^{\prime}(I+h-B) \theta h-P(I+h-B)+P^{\prime}(I+h-B) B .
$$

The first term is the producer benefit and the second and third terms give the marginal fiscal cost. It is straightforward to verify using (1) that this marginal benefit is positive if $B<B^{*}(I)$ and negative if $\mathrm{B}>\mathrm{B}^{*}(\mathrm{I})$, where: 


$$
B^{*}(I)=\left(\frac{(1+\alpha \theta) h+I-\bar{Q}}{1+\alpha}\right)
$$

Assumption $\mathrm{I}$ implies that this is always less than $\mathrm{I}+\mathrm{h}$, ensuring positive consumption. Thus, the optimum is given by $B^{*}(I)$ where this is positive, which is where $1 \geq \bar{Q}-(1+\alpha \theta) h$, and zero elsewhere ${ }^{17}$. Since consumption in period 2 is equal to $(\mathrm{I}+\mathrm{h}-\mathrm{B}),(5)$ implies consumption of:

$$
Q^{*}=\frac{\bar{Q}+\alpha I+(1-\theta) \alpha h}{(1+\alpha)}
$$

for $\mathrm{I} \geq \overline{\mathrm{Q}}-(\mathrm{I}+\alpha \theta) \mathrm{h}$ and $(\mathrm{I}+\mathrm{h})$ elsewhere. Thus, we can write the maximized welfare function under the assumption of an active policy as follows:

$$
W^{*}(I)=\left\{\begin{array}{l}
W(0, I) \quad \text { if } I \leq \bar{Q}-(1+\alpha \theta) h \\
\frac{\alpha^{\alpha}}{(1+\alpha)^{(1+\alpha)}}(\bar{Q}-I+(\theta-1) h)^{(1+\alpha)} \text { if } I \in[\bar{Q}-(1+\alpha \theta) h, \bar{Q}+(\theta-1) h] \\
0 \quad \text { if } I>\bar{Q}+(\theta-1) h .
\end{array}\right.
$$

It is important to observe that this is a decreasing function. An increase in the overhang of stocks on the market can only hurt the export country government.

${ }^{17}$ For high enough $I$, this implies consumption above $\bar{Q}$ and therefore, by (1), a price of zero. In this case, the government will be indifferent between many values of $B$ which all give a welfare value of zero. For concreteness we still let $B=B^{*}(I)$. 
Now all of this has been based on the assumption that the government will choose an active policy. This will be the optimal action when $\Delta(I) \equiv W^{*}(I)-W(0, I)>K$. From (I) and (3),

$$
W(0, I)=\left\{\begin{array}{l}
(\bar{Q}-I-h)^{\alpha} \theta h \text { if } I \leq \bar{Q}-h \\
0 \text { if } I \geq \bar{Q}-h .
\end{array}\right.
$$

Figure 1 shows the determination of the gain from intervention function $\Delta(\mathrm{I})$. Note that with $\alpha<1, W(0,1)$ is a concave function of I wherever it is positive, and $W^{*}(I)$ is convex. Since the envelope theorem guarantees that they have the same derivative with respect to $I$ at $\mathrm{I}=\overline{\mathrm{Q}}-(1+\alpha \theta) \mathrm{h}$, this guarantees that $\Delta(\mathrm{I})$ is strictly increasing from $\overline{\mathrm{Q}}-(1+\alpha \theta) \mathrm{h}$ to $\overline{\mathrm{Q}}-\mathrm{h}$. Thereafter, $\Delta(I)$ decreases because $W^{*}(I)$ does. Thus, $\Delta$ is a quasiconcave function with a support of $[\bar{Q}-(1+\alpha \theta) h, \bar{Q}+(\theta-1) h]$ and a maximum at $\bar{Q}-h$. Denote this maximum by $\bar{\Delta}$. The shape of $\Delta$ can be readily interpreted. First, the gain from intervention is small when the overhang (I) is small because in that case it is not optimal for the government to do much even if it has incurred the fixed cost of intervention. This is so because the marginal fiscal cost of procurement is high and the producer price benefit is small -- both because the price is already close to the maximum. (Recall (4) and the assumed concavity of the demand curve.) Second, the gain from intervention is small when the overhang is very large because then in order to keep the price from falling very close to zero the government must acquire huge stocks and therefore incur a huge fiscal cost. Thus, the optimal policy is to allow the price to fall quite close to zero and therefore welfare is close to what it would be without intervention. Thus, with I small, welfare is near its ideal level even if government does nothing; with I large, the situation is fairly hopeless and nothing will help much. It is only 
for intermediate levels of the overhang that there is much of a benefit from intervention.

Thus, if $K \in(0, \bar{\Delta})$, it is optimal to establish a price support program if and only if $I \in\left(I^{\prime}, I^{\prime \prime}\right)$, where $I^{\prime}$ is (as shown in Figure 1) a number in the interval $(\bar{Q}-(1+\alpha \theta) h, \bar{Q}-h)$, $I^{\prime \prime}$ is in the interval $(\bar{Q}-h, \bar{Q}+(\theta-1) h)$, and $\Delta\left(I^{\prime}\right)=\Delta\left(I^{\prime \prime}\right)=K$. Thus, equilibrium government procurement equals $B^{*}(I)$ if $I \in\left(I^{\prime}, I^{\prime \prime}\right)$ and zero if $I \notin\left(I^{\prime}, I^{\prime \prime}\right)$, and equilibrium consumption equals $Q^{*}\left(I^{*}\right)$ if $I \in\left(I^{\prime}, I^{\prime \prime}\right)$ and $(I+h)>Q^{*}\left(I^{*}\right)$ if $I \notin\left(I^{\prime}, I^{\prime \prime}\right)$. Denote the equilibrium consumption by $Q^{c}(I)$. Figure 2 shows the price, $P\left(Q^{c}(I)\right)$, as a function of $I$. It is the heavy, broken curve, decreasing except for the upward jump at $I=I^{\prime}$. At that point the government is indifferent between establishing price supports and inaction, and a small increase in the overhang of inventories makes it decide to establish supports, with a consequent jump in price. Similarly, the curve jumps down at $I=I^{\prime \prime}$, where the government is indifferent again between the two courses.

It is immediate that a drop in administrative costs raises the likelihood of price supports ceteris paribus. Precisely, differentiating $\Delta\left(\mathrm{I}^{\prime}\right)=\mathrm{K}$ and $\Delta\left(\mathrm{I}^{\prime \prime}\right)=\mathrm{W}^{*}\left(\mathrm{I}^{\prime \prime}\right)=\mathrm{K}$ show that $\mathrm{I}^{\prime}$ is increasing in $\mathrm{K}$ and $\mathrm{I}^{\prime \prime}$ is decreasing in $\mathrm{K}$. Similarly, $\mathrm{I}^{\prime}$ is decreasing in $\theta$ and $\mathrm{I}^{\prime \prime}$ is increasing in $\theta^{18}$ : an increase in the importance of redistributive politics makes price supports more likely, ceteris paribus. Further,

$$
\lim _{K} I^{\prime}=\bar{Q}-(1+\alpha \theta) h \text {, and } \lim _{K} I^{\prime \prime}=\bar{Q}+(\theta-1) h, \text { while }
$$

\footnotetext{
${ }^{18}$ We need to use the envelope result that $\left(W^{*}(I)\right)^{\prime}=-P\left(I+h-B^{*}(I)\right)$ where $B^{*}(I)>0$. We get $\partial \mathrm{I}^{\prime} / \partial \theta=\mathrm{h}\left[\mathrm{P}\left(\mathrm{I}^{\prime}+\mathrm{h}\right)-\mathrm{P}\left(\mathrm{I}^{\prime}+\mathrm{h}-\mathrm{B}^{*}\left(\mathrm{I}^{\prime}\right)\right)\right] /\left[-\mathrm{P}\left(\mathrm{I}^{\prime}+\mathrm{h}-\mathrm{B}^{*}\left(\mathrm{I}^{\prime}\right)\right)-\mathrm{P}^{\prime}\left(\mathrm{I}^{\prime}+\mathrm{h}\right) \theta \mathrm{h}\right]$. The denominator is positive because it is equal to $\Delta^{\prime}\left(I^{\prime}\right)$, which is positive because $I^{\prime}<\bar{Q}-h$ (see Figure 1 ). Thus, the derivative is negative. For $I^{\prime \prime}$, we get $\partial I^{\prime \prime} / \partial \theta=h>0$.
} 


$$
\lim _{K \rightarrow \Delta} I^{\prime}=\lim _{K \rightarrow \Delta} I^{\prime \prime}=\bar{Q}-h
$$

(See Figure 1.) Finally, $I^{\prime} \rightarrow 0$ as $\theta \rightarrow \infty$ and $I^{\prime \prime} \rightarrow \infty$ as $\theta \rightarrow \infty$. In other words, if the producers are sufficiently powerful, there will be price supports regardless of the condition of the market.

3. B. Period 1: Speculative equilibrium: the rise of bubbles, and endogenous volatility.

Now we can put this together with the condition that speculative profits must be zero to determine the equilibrium price. Essentially, this means finding solutions for $I$ to (2), with the equilibrium $\mathrm{B}$ as a function of $\mathrm{I}$ on the right hand side. This is illustrated in Figure 2. Each of the upward sloping curves shows the period 1 price as a function of $I$ for a different value of initial stocks S. As indicated above, the heavy, broken, downward sloping curve shows the period 2 price as a function of I. For a given $S$, an intersection of the two curves gives an equilibrium level of $I$. For initial stocks of $S_{w}$ as shown in panel (a), the unique equilibrium level of inventory demand is $I_{w}$, which gives rise to a period 2 policy of laissez faire.

The case of initial stocks $S_{x}$, as shown in panel (b), is a marked contrast. Here, there are no equilibria, $I_{x 1}$ and $I_{x 2}$. The former results in a low price in both periods and a policy of laissez-faire, while the second results in a high price in both periods and a policy of price supports. The reason is that if speculators accumulate stocks up to the level $I_{x 2}$, and the government then does nothing, the release of those stocks will push the price down to a level that the government would find disastrous. This justifies incurring the fixed cost to establish 
price supports; but once that cost has been incurred, an aggressive storage policy is optimal, leading to a price above $\mathrm{P}\left(\mathrm{I}_{\mathrm{x} 1}+\mathrm{h}\right)$, even though the price that would have resulted from inaction is well below $\mathrm{P}\left(\mathrm{I}_{\mathrm{x} 1}+\mathrm{h}\right)$. Thus, with $\mathrm{S}=\mathrm{S}_{\mathrm{x}}$, the equilibrium price is indeterminate. It could remain at the low level, or it could be pushed to the high level by a self-fulfilling bullish impulse of speculators. It is in this sense that the presence of government can generate a bubble at states like $\mathrm{S}_{\mathrm{x}}$.

Finally, with initial stocks of $S_{y}$ in panel (a), there is no nonstochastic equilibrium ${ }^{19}$. If speculators store 1 " or more, there will be no price supports, and they will suffer capital $\operatorname{losses}^{20}$. If they store less, there will be price supports and they will enjoy positive capital gains. Both outcomes are inconsistent with market clearing. One possible solution is to allow government to randomize when it is indifferent. Using this escape, we have an equilibrium in which speculators store $I "$ and in period 2 the government establishes price supports with probability $\rho\left(\mathbf{S}_{y}\right)$, where:

$$
\rho\left(S_{y}\right)=\frac{P\left(S_{y}+h-I^{\prime \prime}\right)}{P\left(I^{\prime \prime}+h-B^{*}\left(I^{\prime \prime}\right)\right)} \in(0,1),
$$

and the government chooses laissez faire with probability $\left(1-\rho\left(\mathbf{S}_{\mathrm{y}}\right)\right)$. Needless to say, this is a strained description of policy formation in practice.

A more satisfying way of analyzing this case is as follows. Consider $\delta>0$ and suppose

${ }^{19}$ There is also a range of values between $S_{x}$ and $S_{y}$, omitted to avoid cluttering the diagram, with a unique equilibrium in which price supports are established. See the next subsection.

${ }^{2}$ Strictly speaking, this will push the period 2 price all the way down to zero; obviously, this is an artifact of the simple demand curve form used here; more realistic demand curves with a similar shape would give the same result with a low but positive price. 
that $\varepsilon$ is a random variable, with mean zero, a continuous distribution, and support on $[-\delta, \delta]$, which is realized in period 2. Further, suppose that $\theta=\bar{\theta}+\varepsilon$, where $\bar{\theta}$ is a constant known to all. Thus, there is some small uncertainty ex ante about how political forces will play out. For initial stocks of $S_{w}$ or $S_{k}$, equilibrium will be almost exactly as described above provided that $\delta$ is sufficiently small; but for $S_{y}$, the equilibrium level of $I$ will be such that for $\varepsilon$ greater than some critical value $\bar{\varepsilon}$, supports will be established; for $\varepsilon \leq \bar{\varepsilon}$, supports will not be established; and the probability that $\varepsilon>\bar{\varepsilon}$ is equal to $\rho\left(\mathbf{S}_{y}\right)$, as defined above. This is an equilibrium for any positive value of $\delta$, no matter how small. Thus, policy in equilibrium turns on tiny variations in the producers' political clout; the deciding factor may be a senator's bad head cold on the day of the floor debate, making him less forceful than usual. As $\delta$ goes to zero, the set of values of I for which $\varepsilon$ is the deciding factor becomes infinitesimal, but the set of values of initial stocks $S$ that give rise to a value of $I$ in this range does not. Thus, the interaction between speculation and the political process takes tiny, inconsequential variations in the supply and demand for price supports and magnifies them into significant sources of uncertainty about future policy. In this sense, this interaction adds volatility to a market that would otherwise have almost none.

In addition, if in between periods 1 and 2 there was a brief trading period during which information about $\varepsilon$ was revealed, the price would fluctuate sharply with each piece of news that had much effect on the conditional probability that $\varepsilon>\bar{\varepsilon}$. Since with $\delta$ small these fluctuations will entail otherwise quite insignificant information, this would appear to outside observers to represent "excess volatility" or irrationality in the reactions of market participants, and yet it would be the result of fully rational competitive behaviour. It is worth 
pointing out that there are times when commodity markets appear to behave much like this, occurring precisely in periods of glut as suggested by the model.

For example, in March 1992 the coffee market was depressed by longstanding surpluses. There were at the time no price supports, and the market's assessment of the likelihood of new supports appears to have fluctuated widely based on fairly small bits of news. On March 4, near futures prices in New York fell by $4.7 \%$ because there was no announcement at the end of a meeting of producers ${ }^{21}$. The next day they fell an additional $2.4 \%$, reportedly because Brazil failed to make its intentions clear ${ }^{22}$. On March 6 , they shot up by $4.7 \%$ because an association of Brazilian planters voted to support in principle talks on resuming export quotas ${ }^{23}$. On March 30 , they plunged $3.2 \%$ on news that the Brazilian Foreign Minister was resigning ${ }^{24}$. In a similar vein, on February 8, 1993, prices plunged by $8.5 \%$ when an International Coffee Association meeting in London on the possibility of new supports adjourned without progress ${ }^{25}$; talks resumed shortly thereafter. Each of these pieces of news is of tiny consequence when viewed in its context in the long process of international negotiations, and yet each engendered a dramatic market response. It appears that in both cases traders understood market conditions to be such that a tiny perturbation could make the difference between aggressive supports and no supports; in other words, the action of market

\footnotetext{
${ }^{21}$ New York Times, 3/5/1992, p. D19.

${ }^{22}$ New York Times, 3/6/92, p. D13.

${ }^{23}$ New York Times, 3/7/1992, p. 48

${ }^{24}$ New York Times, March 31, 1992, p. D18.

${ }^{25}$ New York Times, 2/9/1993, p. D17.
} 
forces had pushed the market to a point like $I=I^{\prime \prime}$ in Figure 2.

Thus, we see at least three different kinds of equilibrium, depending on the level of initial stocks and the local effect of a rise in stocks on government incentives. The next subsection characterizes fully which type of equilibrium will occur for which portion of the state space

3. C. A full characterization and comparative statics.

Denote the smallest $S$ consistent with multiple equilibria by $\underline{S}^{m}$. Since increasing $S$ slides the upward-sloping period 1 price curve to the right through the diagram of Figure 2, $\underline{S}^{m}$ is given by the point at which this curve just touches the active policy portion of the period 2 price curve; see Figure 3. $\underline{S}^{\mathrm{m}}$ is thus defined by:

$$
\underline{S}^{m}+h-I^{\prime}=I^{\prime}+h-B^{\prime \prime}\left(I^{\prime}\right),
$$

or, using (5),

$$
\underline{S}^{\mathrm{m}}=\frac{\overline{\mathrm{Q}}+(1+2 \alpha) \mathrm{I}^{\prime}-(1+\alpha \theta) \mathrm{h}}{(1+\alpha)}
$$

Similarly, denote the maximum $\mathrm{S}$ consistent with multiple equilibria by $\overline{\mathrm{S}}^{\mathrm{m}}$. Again using Figure 3, this must be given either by the point at which the period 1 price curve just leaves the period 2 passive price curve -- corresponding to the value of $S$ denoted as $\bar{S}_{1}$ in Figure 3 - or the point at which the period 1 price curve just leaves the period 2 active price curve -corresponding to the value of $\mathbf{S}$ denoted as $\bar{S}_{2} . \quad \bar{S}^{\text {m }}$ is the smaller of these values. We can calculate:

$$
\overline{\mathrm{S}}_{\mathrm{l}}=2 \mathrm{I}^{\prime}
$$




$$
\overline{\mathrm{S}}_{2}=\frac{\overline{\mathrm{Q}}+(1+2 \alpha) \mathrm{I}^{\prime \prime}-(1+\alpha \theta) \mathrm{h}}{(1+\alpha)}
$$

Similarly, defining $\left(\underline{S^{r}}, \overline{\mathbf{S}}^{r}\right)$ as the interval on which the equilibrium is random, we find that $\underline{S}^{\mathrm{r}}$ is the larger of $\overline{\mathrm{S}}_{1}$ and $\overline{\mathrm{S}}$, , (so $\underline{\mathrm{S}}^{\mathrm{I}} \geq \overline{\mathrm{S}}^{\mathrm{m}}$ ), and $\overline{\mathrm{S}}^{\mathrm{r}}=\overline{\mathrm{Q}}+\mathrm{I}^{\prime \prime}-\mathrm{h}$. Thus, we have the following proposition, which partitions the state space into five portions.

Proposition 1. (i) If $\mathrm{S} \in\left[0, \underline{\mathrm{S}}^{\mathrm{m}}\right]$, there is one equilibrium, and it involves no price supports.

(ii) If $S \in\left(\underline{S}^{m}, \bar{S}^{m}\right)$, there are two equilibria, one with price supports and the other without.

(iii) If $S \in\left[\overline{\mathrm{S}}^{\mathrm{m}}, \underline{\mathrm{S}}^{\mathrm{t}}\right]$, there is one equilibrium, in which there are no price supports if $\overline{\mathrm{S}}_{2}<\overline{\mathrm{S}}_{1}$ but there are price supports if $\overline{\mathrm{S}}_{2}>\overline{\mathrm{S}}_{1}$.

(iv) If $S \in\left(\underline{S}^{r}, \bar{S}^{r}\right)$ there is no non-stochastic equilibrium, but there is an equilibrium with random policy.

(v) If $S \geq \bar{S}^{r}$, there is one equilibrium, and it involves a price of zero in both periods.

A corollary is that very high prices are always followed by certain laissez faire, while very low prices are always followed by policy uncertainty and price volatility (leaving aside the extreme case of a zero price $)^{26}$.

A natural question is: Under what circumstances are the various types of equilibria

\footnotetext{
${ }^{26}$ Essentially a version of this proposition was offered by a coffee analyst for Cargill in commenting on recent coffee market volatility in early May, 1991, when she explained:

"When the market gets this depressed, producers normally get together and start discussing the possibility of what can be done." New York Times, May 3, 1991, p. D15.
} 
most likely? As a preliminary to answering this, it is straightforward to show ${ }^{27}$ that there exists a number $\mathrm{K}^{*} \in(0, \bar{\Delta})$ such that if $\mathrm{K}<\mathrm{K}^{*}, \overline{\mathrm{S}}_{2}>\overline{\mathrm{S}}_{1}$ and if $\mathrm{K}>\mathrm{K}^{*}, \overline{\mathrm{S}}_{2}<\overline{\mathrm{S}}_{1}$. Further, $\mathrm{K}^{*}$ is increasing ${ }^{28}$ in $\theta$, so $K=K^{*}$ defines an upward sloping frontier in $(\theta, K)$ space. This neatly partitions the parameter space into a region with high administrative costs and a weak redistributive motive $\left(\mathrm{K}>\mathrm{K}^{*}\right)$, and a region with low administrative costs and a strong redistributive motive $\left(\mathrm{K}<\mathrm{K}^{*}\right)$. (For convenience, we will speak of the function $\mathrm{K}^{*}(\theta)$ and its inverse $\theta^{*}(\mathrm{~K})$ ). This partition tells us something about when bubble equilibria are most likely:

Proposition 2. Bubbles are most likely if administrative costs and the importance of redistributive politics are in an intermediate range. Precisely:

(i) $\left(\overline{\mathrm{S}}^{\mathrm{m}}-\underline{\mathrm{S}}^{\mathrm{m}}\right)$ is increasing in $\mathrm{K}$ when $\mathrm{K}<\mathrm{K}^{*}$ and decreasing when $\mathrm{K}>\mathrm{K}^{*}$.

(ii) Suppose that $K>K^{*}$. Then $\left(\bar{S}^{m}-\underline{S}^{m}\right)>0$, and a small increase in $\theta$ will increase it; but for a sufficiently large increase, the interval on which bubbles occur becomes empty.

Proof: (i) $\left(\overline{\mathrm{S}}_{1}-\underline{S}^{\mathrm{m}}\right)$ is increasing in $\mathrm{I}^{\prime}$ and $\left(\overline{\mathrm{S}}_{2}-\underline{S}^{\mathrm{m}}\right)$ is increasing in $\left(I^{\prime \prime}-I^{\prime}\right)$. Since $I^{\prime}$ is increasing in $\mathrm{K}$ and $\mathrm{I}^{\prime \prime}$ is decreasing in $\mathrm{K}$, the result follows.

(ii) If $\mathrm{K}>\mathrm{K}^{*},\left(\overline{\mathrm{S}}^{\mathrm{m}}-\underline{\mathrm{S}}^{\mathrm{m}}\right)=\left(\overline{\mathrm{S}}_{2}-\underline{\mathrm{S}}^{\mathrm{m}}\right)=(1+2 \alpha)\left[\mathrm{I}^{\prime \prime}-\mathrm{I}^{\prime}\right] /(1+\alpha)$. Recalling footnote 18 , the

${ }^{27}$ Since $I^{\prime}$ is increasing in $\mathrm{K}$ and $I^{\prime \prime}$ is decreasing in $\mathrm{K},\left(\overline{\mathrm{S}}_{2}-\overline{\mathrm{S}}_{1}\right)$ is decreasing in $\mathrm{K}$. It is also continuous in $\mathrm{K}$. Further, as $\mathrm{K} \rightarrow 0, \mathrm{I}^{\prime} \rightarrow \overline{\mathrm{Q}}-(1+\alpha \theta) \mathrm{h}$ and $\mathrm{I}^{\prime \prime} \rightarrow \overline{\mathrm{Q}}+(\theta-1) \mathrm{h}$ (see Figure 1), so $\left(\overline{\mathrm{S}}_{2}-\overline{\mathrm{S}}_{1}\right) \rightarrow \theta(1+2 \alpha) \mathrm{h}>0$. Finally, as $\mathrm{K} \rightarrow \bar{\Delta}, \mathrm{I}^{\prime}, \mathrm{I}^{\prime \prime} \rightarrow(\overline{\mathrm{Q}}-\mathrm{h})$, so $\left(\overline{\mathrm{S}}_{2}-\overline{\mathrm{S}}_{1}\right) \rightarrow-(\alpha \theta /(\mathrm{I}+\alpha)) \mathrm{h}<0$. Q.E.D.

${ }^{28}$ From the previous footnote, $\left(\overline{\mathrm{S}}_{2}-\overline{\mathrm{S}}_{1}\right)$ is decreasing in $\mathrm{K}$, and from footnote 18 , it is increasing in $\theta$. Since $K^{*}$ is defined by $\left(\bar{S}_{2}-\bar{S}_{1}\right)=0$, this establishes the result. 
derivative of this with respect to $\theta$ is positive. However, a sufficiently large increase in $\theta$ crosses the $\mathrm{K}=\mathrm{K}^{*}$ frontier, so that $\overline{\mathrm{S}}^{\mathrm{m}}=\overline{\mathrm{S}}_{1}=2 \mathrm{I}^{\prime}$, and as noted above, for sufficiently large $\theta$ holding all else constant, $I^{\prime}=0$. Q.E.D.

This proposition highlights the basic character of the multiple equilibrium outcome: it holds, in a well defined sense, only for intermediate values of the demand for, and supply of, price supports. If the demand for supports is very weak or its supply very reluctant, there will be no supports regardless of speculative behaviour, and equilibrium will be unique. If the demand is very strong or the supply is very quick to accommodate, there will be supports regardless of speculative behaviour, and equilibrium will be unique. It is only for in between levels of these variables that multiple equilibria become a factor. A similar result applies to the random equilibrium:

Proposition 3. Random equilibria are most likely when administrative costs and the importance of redistributive politics are in an intermediate range. However, no matter how strong the redistributive motive is, there is always the possibility of a random equilibrium. Precisely:

(i) For any $\theta, \underline{S}^{r}$ is minimized with respect to $K$ by $K=K^{*}(\theta)$; and for any $K, \underline{S}^{r}$ is minimized with respect to $\theta$ at the point at which $\theta=\theta^{*}(K)$.

(ii) For any $\theta,\left(\bar{S}^{r}-\underline{S}^{r}\right)$ is maximized at $K=K^{*}(\theta)$, and for any $K$, it is maximized at $\theta=\theta^{*}(K)$. (iii) $\operatorname{Lim}_{\theta \rightarrow \infty}\left[\left(\overline{\mathbf{S}}^{\mathrm{r}}-\underline{\mathbf{S}}^{\top}\right)\right]>0$

Proof: Immediate, once one verifies mechanically that $\partial \overline{\mathbf{S}}_{1} / \partial \theta<0 ; \partial \overline{\mathbf{S}}_{1} / \partial \mathrm{K}>0 ; \partial \overline{\mathbf{S}}_{2} / \hat{c} \theta>0$; 
$\partial \overline{\mathbf{S}}_{2} / \partial \mathrm{K}<0 ; \hat{\partial}\left[\overline{\mathbf{S}}^{\mathrm{r}}-\overline{\mathbf{S}}_{1}\right] / \partial \theta>0 ; \partial\left[\overline{\mathbf{S}}^{\mathrm{r}}-\overline{\mathbf{S}}_{1}\right] / \partial \mathrm{K}<0 ; \partial\left[\overline{\mathbf{S}}^{\mathrm{r}}-\overline{\mathbf{S}}_{2}\right] / \partial \theta=0 ; \partial\left[\overline{\mathbf{S}}^{\mathrm{r}}-\overline{\mathbf{S}}_{2}\right] / \partial \mathrm{K}>0 . \quad$ Q.E.D.

The reasoning here is similar to that for the previous proposition. However, no matter how large $\theta$ becomes, there will always exist a level of $\mathrm{S}$ high enough to make government indifferent between supports and no supports in equilibrium; and as $\theta$ rises, the rising gap between the supported and unsupported prices for any I means that the range of initial stocks for which this happens does not vanish.

\section{Comparison with Full Commitment: the Failings of Discretion.}

\section{A. The full commitment solution.}

The assumed inability of the government to commit itself leads in general to a suboptimal outcome. There are three ways in which it could be suboptimal: It could result in the wrong level of price supports, it could lead to no supports when supports are optimal, and vice versa. Thus, equilibrium may err in choice of level or in choice of regime, with one possible failure of level and two of regime choice. It will be seen that all three failures are possible, but to see this, we first need to review the optimization problem under commitment ${ }^{29}$.

\footnotetext{
${ }^{29}$ In general, it is possible that the full optimum under commitment will involve randomization as a way of circumventing the fixed cost. Here we will examine only nonrandom solutions, for simplicity. I am grateful to Joshua Aizenman for pointing this out to me.
} 
If the Home government is able to commit itself publicly to a value of $B$ at the beginning of period 1 , it chooses $B$ to maximize the full two-period welfare function:

$$
P(S+h-I) \theta h+P(I+h-B)[\theta h-B]
$$

minus administrative costs if any, understanding that its choice of B will determine I through the market clearing condition (2). Substituting this market clearing condition in, the problem is to maximize:

$$
\mathrm{V}(\mathrm{B}, \mathrm{S})-\phi(\mathrm{B}) \mathrm{K}
$$

subject to the constraint that $\mathrm{B} \in[0, \mathrm{~S}+2 \mathrm{~h}]$, where $\phi$ is as defined in the case of discretion, and:

$$
V(B, S)=P\left(\frac{S-B}{2}+h\right)[2 \theta h-B]
$$

Assume for the moment that $\mathrm{B}>0$. The marginal benefit of promised procurement is then:

$$
V_{B}(B, S)=-\frac{1}{2} P^{\prime}\left(\frac{S-B}{2}+h\right)[2 \theta h-B]-P\left(\frac{S-B}{2}+h\right) .
$$

This is positive if $B<\tilde{B}(S)$ and negative if $B>\tilde{B}(S)$, where 


$$
\tilde{B}(S)=\left(\frac{2(1+\alpha \theta) h+S-2 \bar{Q}}{1+\alpha}\right)
$$

Assumption 1 implies that this is always smaller than $S+2 h$. Thus, if $\tilde{B}(S)<0$, the optimum is $\mathrm{B}=0$; and in all other cases, the optimum is $\mathrm{B}=\tilde{\mathrm{B}}(\mathrm{S})$. This gives a maximized welfare level of:

$$
\tilde{V}(S)=\left\{\begin{array}{l}
V(0, S) \quad \text { if } S \leq 2[\bar{Q}-(1+\alpha \theta) h] \\
\frac{2 \alpha^{\alpha}}{(1+\alpha)^{(1+\alpha)}}\left(\bar{Q}-\frac{S}{2}+(\theta-1) h\right)^{(1+\alpha)} \text { if } \frac{S}{2} \in[\bar{Q}-(1+\alpha \theta) h, \bar{Q}+(\theta-1) h] \\
0 \quad \text { if } S>2[\bar{Q}+(\theta-1) h] .
\end{array}\right.
$$

By contrast, if no price supports are established, the welfare level is:

$$
V(0, S)=\left\{\begin{array}{l}
2\left(\bar{Q}-\frac{S}{2}-h\right)^{\alpha} \theta h \text { if } S \leq 2[\bar{Q}-h] \\
0 \text { if } S>2[\bar{Q}-h] .
\end{array}\right.
$$

Defining the gain from price supports as $\tilde{\Delta}(S)=\tilde{V}(S)-V(0, S)$, the government will commit to supports if and only if $\tilde{\Delta}(S)>K$. This decision has qualitatively all of the same properties as the second-period problem under discretion, and indeed, it can quickly be verified that $\tilde{\Delta}(\mathrm{S})=2 \Delta(\mathrm{S} / 2)$ for all $\mathrm{S}$. 
4. B. The level of price supports.

Substituting the market clearing condition (2) into (4) yields the marginal benefit to procurement in period 2 in equilibrium under discretion, when $B>0$ :

$$
W_{B}\left(B, \frac{S+B}{2}\right)=-\frac{1}{2} P^{\prime}\left(\frac{S-B}{2}+h\right)[\theta h-B]-P\left(\frac{S-B}{2}+h\right) .
$$

For any $\mathrm{B}$, this is strictly less than the marginal benefit under commitment as shown in (8). This and the quasiconcavity of $\mathrm{W}$ and $\mathrm{V}$ yield a strong conclusion about the comparison of the two.

Proposition 4. If the equilibrium under discretion and the optimum under commitment both involve price supports, then the level of procurement and hence the price are strictly higher under commitment than under discretion.

Thus, if both regimes involve price supports, then the discretionary solution is inferior because it is not aggressive enough (from the point of view of the exporting country, of course). The reason is clear from the expressions for $V_{B}$ and $W_{B}$ : An increase in period 2 procurement commitment at the beginning of period 1 leads speculators to bid up the price right away, giving two periods of benefit to producers. However, an increase in ex post procurement in period 2 raises the price in period 2 only, thus giving farmers only one period of benefit. Thus, although the marginal cost of procurement is the same in both cases, at a 
given procurement level the marginal benefit to the government at the moment it makes its decision is always smaller under discretion. Speculators, understanding this, will always bid the price up to a lower level under discretion than under commitment.

Note that moving from discretion to commitment in this case has redistributional implications within Home: it makes taxpayers poorer and farmers richer. However, the loss to taxpayers is necessarily less than $\theta$ times the gain to producers.

\section{C. Failures of regime choice.}

The first possible error of regime choice is that the discretionary equilibrium could lead to laissez faire while the full optimum calls for supports. We will say in this case that the government is "stuck in neutral:" It would like to have an activist policy, but it is unable to do anything because it cannot convince speculators to give it a hand. Second, the discretionary equilibrium could lead to price supports while the full optimum calls for laissez faire. We will then say that the government has been "trapped" by the activity of speculators into providing price supports. Both failures can occur under the right circumstances.

First, for the government to get stuck in neutral we need $\tilde{\Delta}(\mathrm{S})>\mathrm{K}$, so that supports are desirable, while $\Delta(\mathrm{S} / 2) \leq \mathrm{K}$, so that laissez faire is an equilibrium under discretion. (Recall that if no price supports are expected, (2) implies that $I=S / 2$.) This is possible whenever $\tilde{\Delta}(\mathrm{S})>\Delta(\mathrm{S} / 2)$; but since $\tilde{\Delta}(\mathrm{S})=2 \Delta(\mathrm{S} / 2)$, this is true whenever $\tilde{\Delta}(\mathrm{S})$ is positive. This means that it is generically possible for the government to get stuck in neutral under discretion, provided only that $\mathrm{K}$ lies in the right range. 
Proposition 5. Whenever price supports are desirable, the discretionary government can nonetheless get stuck in neutral provided administrative costs lie in an intermediate range. Precisely, supports are optimal and yet $\mathrm{B}=0$ is a discretionary equilibrium if and only if:

(i) $\mathrm{S} \in[2(\overline{\mathrm{Q}}-(\mathrm{l}+\alpha \theta)), 2(\overline{\mathrm{Q}}+(\theta-1) \mathrm{h})]$;

(ii) $\mathrm{K} \in[\Delta(\mathrm{S} / 2), 2 \Delta(\mathrm{S} / 2)]$.

This interval for $\mathrm{K}$ is at its widest in the interior of the range, when $\mathrm{S}=2[\overline{\mathrm{Q}}-\mathrm{h}]$.

This result comes from essentially the same source as Proposition 4: Ex post, the government has a much smaller stake in price supports than it did ex ante. If $\mathrm{S}$ and $\mathrm{K}$ are in the indicated range, the government would be willing to incur the fiscal cost of supports in return for two periods of high price, but not for only one. This is why laissez faire is simultaneously undesirable and an equilibrium.

By contrast, the conditions under which the government can be "trapped" into providing supports are much more complex to derive. The Appendix derives the following: 
Proposition 6. (i) The government can be "trapped" by speculators into providing price supports in a neighborhood of $S=2[\overline{\mathrm{Q}}-(1+\theta \alpha /(1+\alpha)) \mathrm{h}]$ if and only if demand is sufficiently concave: precisely, if and only if $\alpha<0.925316$.

(ii) The government can be trapped into establishing supports with $\mathrm{S}$ near $2[\bar{Q}-(1+\theta \alpha) h]$ if and only if demand is sufficiently concave; precisely, if and only if $\alpha<1 / \sqrt{ } 2$.

(iii) Whenever the government can get trapped into providing supports, a drop in $\mathrm{K}$ will put it into the range where the government can get stuck in neutral.

(iv) Whenever the government can get trapped into providing supports, both supports and laissez faire are equilibria.

Proposition 6 shows that it is possible for the government to be trapped by speculators into providing price supports provided that demand is sufficiently concave. The reason for the importance of concavity is clear. Let $I^{*}(S)$ be the inventories held in a discretionary equilibrium $^{30}$ with price supports and initial stocks S; see Appendix equation (A.1). Denote by $Q_{L}=(S / 2+h)$ laissez-faire consumption per period; by $Q_{D}=\left[\left(S-B^{*}\left(I^{*}(S)\right)\right) / 2+h\right]$ perperiod consumption under a discretionary equilibrium with price supports; by $Q_{D L}=$ $\left[\left(S+B^{*}\left(I^{*}(S)\right)\right) / 2+h\right]$ second-period consumption off the equilibrium path of the discretionary equilibrium with supports, in which the government chooses laissez-faire after the market has anticipated supports: and by $\mathrm{Q}_{C}=[(\mathrm{S}-\tilde{\mathrm{B}}(\mathrm{S})) / 2+\mathrm{h}]$ per-period consumption under commitment

\footnotetext{
${ }^{30}$ Here we assume that the discretionary equilibrium is nonrandom, which is the only case of interest because we are discussing a situation in which the government would not choose supports under full commitment. When the discretionary equilibrium is random, $\Delta(\mathrm{S} / 2)>\mathrm{K}$ because pure laissez faire is not an equilibrium, but then $\tilde{\Delta}(\mathrm{S})=2 \Delta(\mathrm{S} / 2)>\mathrm{K}$ and the government would choose supports under commitment.
} 
with the optimal positive level of supports, $\tilde{B}(S)$. Let $\mathrm{p}_{\mathrm{L}}=\mathrm{P}\left(\mathrm{Q}_{\mathrm{T}}\right)$, and so on; $\mathrm{p}_{\mathrm{DL}}<\mathrm{p}_{\mathrm{t}}<\mathrm{p}_{\mathrm{D}}$ $<\mathrm{p}_{C}$. The condition that price supports are not optimal under commitment implies:

$$
\begin{gathered}
K \geq 2\left(p_{C}-p_{L}\right) \theta h-p_{C} \tilde{B} \geq 2\left(p_{D}-p_{L}\right) \theta h-p_{D} B^{*}\left(I^{*}(S)\right), \text { so } \\
2\left(p_{D}-p_{L}\right) \theta h \leq p_{D} B^{*}\left(I^{*}(S)\right)+K .
\end{gathered}
$$

In other words, the price rise is too small relative to the fiscal cost of the policy to be justified (for the optimal level, and a fortiori for the sub-optimal $\mathrm{p}_{\mathrm{D}}$ ). On the other hand, the condition that supports are an equilibrium implies that:

$$
\left(p_{D}-p_{D L}\right) \theta h>p_{D} B^{*}\left(I^{*}(S)\right)+K
$$

In other words, the price drop if the government disappoints the market is large relative to the fiscal cost of the policy. Putting (12) and (13) together yields:

$$
2\left(p_{D}-p_{L}\right)<\left(p_{D}-p_{D L}\right)
$$

However, since $\left(Q_{D L}-Q_{D}\right)=B^{*}\left(I^{*}(S)\right)$ and $\left(Q_{L}-Q_{D}\right)=B^{*}\left(I^{*}(S)\right) / 2$, this is the same as the statement that the arc slope of the demand curve between $Q_{D}$ and $Q_{D L}$ is greater in absolute value than it is between $Q_{D}$ and $Q_{L}$. But this is a statement of concavity. The point is that in this setting the benefit to policy arises from a rise in price. For the government to be trapped 
into establishing supports, the prospects for a rise in price must be modest ex ante, but the threat of a price drop must be large ex post if the market is forced to a lower point on the demand curve by an accumulation of stocks. This requires strictly concave demand.

\section{D. The Welfare Loss from the "Trap".}

It was noted above (in Proposition 6) that when the government can be trapped into providing supports, there are two equilibria. In that situation it is easy to show that the loss in world welfare from the equilibrium with supports is always large. For concreteness here, set $\theta=1$. If we measure world welfare by the unweighted sum of each agent's surplus, we need to account for the change in producers', consumers', taxpayers' and speculators' surplus. Using the notation just introduced, the difference in producers' surplus between the two equilibria is $2\left(p_{D}-p_{L}\right) h$. The change in consumers' surplus is:

$$
-2 \int_{p_{L}}^{p_{D}} D(\rho) d \rho<-\left(p_{D}-p_{L}\right)\left[S+2 h-\frac{B^{*}\left(I^{*}(S)\right)}{2}\right],
$$

where the function $D$ is the inverse of the function $P$ and the inequality follows by the concavity of demand. The change in taxpayers' surplus is $-p_{D} B^{*}\left(I^{*}(S)\right)-K$. The change in speculators' surplus is simply the change in the value of their original stock, $\left(p_{D}-p_{L}\right) S$. Adding all of these up, we find the following lower bound for the change in world welfare ${ }^{31}$ :

\footnotetext{
${ }^{31}$ In deriving this bound, use is made of (5), (A.1), (14), (12), and the fact, derived in the Appendix, that $\mathrm{S}$ must be no greater than $\tilde{S}$ " for the "trap" to be possible, where $\tilde{\mathrm{S}}$ " is a constant defined in the Appendix.
} 


$$
-\left[1+\left(\frac{1+\alpha}{1+2 \alpha}\right)\right]\left(p_{D}-p_{L}\right) h .
$$

Thus, the world welfare loss is always at least as great as the ise in value of the per period harvest. If $\alpha$ is small, the lower bound is close to the rise in the value of both harvests, or the total value of rents transferred to producers ${ }^{32}$.

\section{Qualifications and Partial Remedies.}

It is worth mentioning four areas in which this model's assumptions have been restrictive, and the implications of loosening them.

(i) Government delay. In this model, speculators can act in period 1 but (apart from the case of full commitment), the government is hamstrung until period 2. The assumption that government cannot move as quickly as speculators is hardly unrealistic; major farm legislation and international commodity agreements both take months or years to negotiate and then a further delay to implement. However, it should be pointed out that if that assumption is relaxed and government as well as speculators can store in period 1, some but not all of the phenomena derived above disappear.

\footnotetext{
${ }^{32}$ This is, of course, a form of rent-seeking problem, but in contrast with the classic analyses of rent-seeking (Krueger (1974), Posner (1975)), we have a lower bound on the welfare loss, and that lower bound is below the total value of rent transferred. There are three key reasons for the difference. First, there is only one agent engaged in rent-seeking, namely the Home government; competition in rent-seeking is key to those classic accounts. Second, the fact that the rent-seeking agent is serving two interest groups complicates matters; the fiscal concern of taxpayers puts a brake on the rent-seeking process in this model. Third, a portion of the rents transferred "leak out" into the hands of foreign speculators.
} 
Suppose that in period 1 the government can choose to store an amount G; after seeing the government's choice of G, the speculators form their expectations of period 2 and the equilibrium level of $\mathrm{I}$ is determined. In period 2, speculators sell all of their stocks but the government may choose to retain an amount B at the end of the period. The government's period 2 objective function is now:

$$
P(G+I+h-B)(\theta h+G-B)-\hat{\phi}(G, B) K
$$

where $\hat{\phi}(G, B)=0$ if $B=0$ or $G>0$ and 1 otherwise ${ }^{33}$. This is to be maximized by choice of $B$ subject to $0 \leq B \leq(G+I+h)$, yielding $\hat{B}(G, I)$. It is immediate to verify that $0 \leq \hat{B}_{\mathrm{I}} \leq \hat{\mathrm{B}}_{\mathrm{G}} \leq 1$, where subscripts indicate partial derivatives. The level of $\mathrm{I}$ is determined by the market clearing condition:

$$
P(S+h-G-I)=P(I+G+h-\hat{B}(G, I))
$$

yielding a function $\hat{\mathrm{I}}(\mathrm{G}, \mathrm{S})$. It is straightforward to verify that $-1 \leq \hat{\mathrm{I}}_{\mathrm{G}} \leq-1 / 2$. Thus, an increase in $\mathrm{G}$ reduces private stocks but less than one-for-one, so consumption falls. This can continue until private stocks are zero if the government wishes.

The conclusion is that a government that can store in period 1 can not suffer from a price support policy that is not aggressive enough. It can solve that problem by choosing an

\footnotetext{
${ }^{33}$ Thus, the assumption here is that administrative costs are incurred only in establishing, not in maintaining, a price support program. Alternative assumptions would reduce the benefit from first-period public storage.
} 
appropriate positive level of $\mathrm{G}$. The reason is that public sector storage gives the government an additional stake in keeping the price high in period 2; speculators, understanding that, expect higher prices in period 2 than they would have otherwise and bid the period 1 price up as well ${ }^{34}$. At the same time, the government's first period purchases will have no direct effect on the present value of the government's objective function because the government, like private speculators, will simply make zero profits on them. Further, obviously it is impossible for the government to be "stuck in neutral" if it can incur the administrative costs and begin storing in period 1. The only possible failure of discretion that remains when government can store in period 1 is that it can be trapped into price supports when they are suboptimal, and this can happen under exactly the same circumstances as previously.

(ii) Futures markets ${ }^{35}$. Futures market transactions can plausibly help the government overcome its commitment difficulties. If the producers do not have access to futures markets but the government takes a position $F$ maturing in period 2, where $F>0$ is short and $F<0$ is long, then the government's period 2 objective function before deducting administrative costs is:

$$
P(I+h-B)[\theta h-B]+p_{t} F-P(I+h-B) F,
$$

\footnotetext{
${ }^{34}$ Note that because of this effect on government incentives, government cannot duplicate the outcome of an equilibrium with private storage by storing an amount equal to what the private sector would have stored otherwise; the mere act of acquiring the speculators' stock will make the speculators want to acquire some more. This is an additional difference between the discretionary situation and commitment; in the latter case, public and private stocks are perfect substitutes.

${ }^{35}$ I am grateful to Bill Lehr for suggesting this section.
} 
where $p_{f}$ is the futures price, which is determined in period 1 . The first term is as before; the last term is the cost of procuring the commodity on the spot market to settle the contract, and the middle term is the revenue from the settlement. (The transaction does not directly affect the period 2 price because the commodity is sold to consumers right after the settlement.) It is straightforward to see that the optimal B is decreasing in F; a short position gives the government a stake in lower prices. As a result, speculators, seeing the government take a short position in period 1 , will bid the period 1 price down and hold smaller inventories than they otherwise would. Analogously, a long position will fulfill exactly the role of government storage outlined above, and convince speculators to bid the price up. In addition, the derivative of $\Delta$ with respect to $F$ is equal to $P(I+h)-P(I+h-B)<0$, so that with a large enough short position, the government can effectively commit not to establish supports. If that happens, the position then has no additional effect on welfare or resource allocation; equilibrium will drive $p_{f}$ to equal the anticipated period 2 spot price $\left(p_{L}\right)$, so the government will make zero profits on its position, and the outcome will be exactly the same as laissez faire. Thus, if the government has access to a futures market with sufficiently long-term contracts it can capture all of the benefits of full commitment.

This optimistic outcome is unlikely in practice, however. First, in practice, commodity futures contracts are typically available only in fairly short maturities, not usually much exceeding a year, and thus could offer only short term commitment. Individually negotiated forward contracts could fill the same function and could conceivably be of much longer term, but the transactions costs from such arrangements are typically higher. Second, in practice any futures contract that is not a hedge on a cash position entails considerable risk. Since 
random variation in supply and demand has been assumed away in this model, that cost does not appear, but it is extremely important in actual trading ${ }^{36}$. Third, aggressive manipulation of futures markets would be likely to run afoul of regulators ${ }^{37}$. Finally, if the government must set up a bureaucracy to engage in futures market transactions in order to avoid getting trapped into a program of price supports, it will incur a considerable amount of administrative cost from that program alone. It may well be that that administrative cost defeats the purpose of avoiding price supports, and that even with the futures market option the government will choose to give up and resign itself to a future with controls.

(iii) Functional form. The functional form for demand used in this model is similar in many respects to linear demand. It has very high elasticity at high prices and very low elasticity at low ones. Any demand curve will behave similarly if there is a maximum price above which sales are zero and there is a maximum quantity which the market will absorb. However, the multiple equilibria observed in this model appear to be impossible to generate

\footnotetext{
${ }^{36}$ There are two important historical cases of a government or government created body attempting to use futures markets in this way. In the first half of the 1980's, the International Tin Council buffer stock manager established large long positions on the London Metals Exchange, in part to convince the market that the announced price support levels were credible. See Anderson and Gilbert (1988) and Gibson-Jarvie (1986). In the late 1970's, Brazil and Columbia apparently tried a similar maneuver on the New York Coffee, Cocoa and Sugar exchange to support coffee prices. See Greenstone (1981). Both episodes were financially disastrous for the protagonists.

${ }^{37}$ See Greenstone (1981) for an account of the relevant issues in the coffee case. U.S. regulators generally are inclined to prosecute anything smacking of manipulation of an exchange, but there is a grey area encountered when the putative manipulator is a sovereign state. At any rate, sustained manipulation would be unlikely to be tolerated. By contrast, the tin case centered on the LME, one of the least regulated of commodity exchanges at the time, but ultimately this was part of the problem; the lack of safeguards paved the way for the 1985 crash. See Gibson-Jarvie (1986) for a detailed account.
} 
with an isoelastic demand curve; with elasticity above unity, $\mathrm{B} \equiv 0$, and with elasticity below unity, $\Delta$ is a decreasing function. In general, whenever government would derive some gross benefit from price supports, and the gain, $\Delta$, from such supports is increasing in the size of the overhang, multiple equilibria are possible; and whenever the gain is decreasing in the overhang, an equilibrium with induced randomness is possible. Which is these will be found in a given case is sensitive to the shape of demand.

(iv) Egalitarianism and risk aversion. We restricted government here to a welfare function that was linear in the surplus of taxpayers and producers. However, if the government's values or the political process places more weight on poorer members, the welfare function will be strictly quasiconcave in the two groups' surpluses ${ }^{38}$. For example, the welfare function could be:

$$
v(P(I+h-B) h)+w(Y-P(I+h-B) B-\phi(B) K),
$$

with $\mathrm{Y}$ equal to taxpayers's income in the absence of commodity policy, $\phi$ as in section 2 , and $\mathrm{v}$ and $\mathrm{w}$ both strictly concave. In this case, for $\mathrm{B}>0, \Delta^{\prime}$ will be given by:

$$
\left[v^{\prime}(P(I+h-B) h) h-w^{\prime}(Y-P(I+h-B) B-K) B\right] P^{\prime}(I+h-B)-v^{\prime}(P(I+h) h) P^{\prime}(I+h) h .
$$

If farmers are sufficiently heavily weighted and if $\mathrm{v}$ is sufficiently concave, the last term,

${ }^{38}$ See, for example, Atkinson (1978) for the social welfare interpretation, and Peltzman (1976) for a political interpretation. 
which is positive, will dominate, implying that the gain function $\Delta$ will always be increasing. This will mean that multiple equilibria will become more important, and regions with the random equilibrium will vanish. The fact that it makes the objective function more concave in I will also make it easier for situations to arise in which the government is "trapped" into providing price supports -- even in cases in which the demand curve is not itself concave. This is important, because in practice egalitarianism is an important impetus behind commodity policies. Gardner (1987) found evidence that U.S. farm commodity policy formation has had a strong egalitarian element in it, responding to a sharp drop in farm incomes as if lower income households have a higher weight. Note that this mathematical conclusion flows also from the standard interpretation of commodity policy as a response to missing insurance markets in the presence of risk aversion (Newbery and Stiglitz, 1981), which could be a valid interpretation here if, say, the initial value of $S$ or $h$ was random and uninsurable for some reason ${ }^{39}$. If this interpretation is right, the model in this paper may have understated the scope for "bubbles" and "traps" in the formation of commodity policy.

\section{Conclusion.}

Perhaps the major point developed in the analysis above is that in analyzing the establishment of a commodities policy, one should take close account of the effect of speculative behaviour on the incentives of government. The kind of market equilibrium that

\footnotetext{
${ }^{39}$ Analogously, this is a common interpretation of much trade protection, some of which would be susceptible to a similar analysis. See Eaton and Grossman (1987) and Baldwin (1981).
} 
emerges when government's incentive to intervene is increasing in private inventories may be dramatically different from that with a decreasing incentive. Further, in both cases the interaction between speculators and government may be rich, and can lead to an increased volatility.

One of the consequences is that the kind of equilibrium that will result depends quite closely on the shape of the demand curve that is perceived by market participants. This suggests a natural direction for empirical enquiry; there are many econometric attempts to estimate demand elasticities in commodity markets, but attempts to test a hypothesis of concavity, for example, are uncommon. It is unlikely that such second-order measurements can be made with much precision on available consumption data for most commodities, since degrees of freedom may be too scarce, but may be worth trying nonetheless.

Casual observation suggests that the perceived shape of demand relations may be quite complex in some cases. For example, in coffee, major price support programs have been established in periods of extreme glut ${ }^{40}$ and in periods of extreme scarcity. ${ }^{41}$ On its face, this would seem to suggest a gain-from-intervention function shaped like an inverted $U$, rather than the quasiconcave hump (recall Figure 1) of the model presented here, and thus a demand curve quite steep at high and low prices but flatter in between. ${ }^{42}$ This would require at least a

${ }^{40}$ This is the case with the original valorizations, beginning in 1906 , and with the original International Coffee Agreement in 1962. Krasner (1973) and Fisher (1972).

${ }^{41}$ This is the case with the withholding program and futures market manipulations of the late 1970's. Greenstone (1981).

${ }^{42}$ It could also be rationalized by a very convex demand curve and a very concave farmer utility function or political support function (as discussed in section 5(iv) above). Distinguishing between these two explanations empirically may be tricky. 
cubic functional specification, and since extremes of price are infrequently visited ${ }^{43}$, identification of such higher derivatives may be difficult.

However, the general point has been made. When commodities policy is treated as endogenous and the commodity is storable, the shape of government incentives as a function of the state of the market is a crucial determinant of the type of equilibrium that will emerge.

${ }^{43}$ This is discussed in some detail by Deaton and Laroque (1992). 


\section{Appendix.}

This appendix derives the following proposition.

Proposition 6. (i) The government can be "trapped" by speculators into providing price supports in a neighborhood of $S=2[\overline{\mathrm{Q}}-(1+\theta \alpha /(1+\alpha)) \mathrm{h}]$ if and only if demand is sufficiently concave: precisely, if and only if $\alpha<0.925316$.

(ii) The government can be trapped into establishing supports with $\mathrm{S}$ near $2[\bar{Q}-(1+\theta \alpha) h]$ if and only if demand is sufficiently concave; precisely, if and only if $\alpha<1 / \sqrt{ } 2$.

(iii) Whenever the government can get trapped into providing supports, a drop in $\mathrm{K}$ will put it into the range where the government can get stuck in neutral.

(iv) Whenever the government can get trapped into providing supports, both supports and laissez faire are equilibria.

It is useful to define for each $S$ the level of inventory demand $I^{*}(S)$ that satisfies $I=\left(B^{*}(I)+S\right) / 2$ for $I . \quad B y(2)$, this is the level of inventories at the beginning of period 2 in a discretionary equilibrium with price supports and with initial stocks equal to $S$. By (5), this is unique and is given by:

$$
I^{*}(S)=\frac{S(1+\alpha)+(1+\alpha \theta) h-\bar{Q}}{(1+2 \alpha)}
$$

The condition under which the government may be "trapped" into providing supports is then simply $\tilde{\Delta}(\mathrm{S}) \leq \mathrm{K}$ and $\Delta\left(\mathrm{I}^{*}(\mathrm{~S})\right)>\mathrm{K}$. Thus, we are looking for conditions under which $\tilde{\Delta}(\mathrm{S})<\Delta\left(I^{*}(\mathrm{~S})\right)$. In doing this, it is useful to define three threshold levels of $\mathrm{S} . \mathrm{S}^{\prime}$ is defined 
as the level of $S$ such that $B^{*}\left(I^{*}(S)\right)$ is equal to zero. $S^{\prime \prime}$ is defined as the smallest solution to $\mathrm{P}\left(\mathrm{I}^{*}\left(\mathrm{~S}^{\prime \prime}\right)+\mathrm{h}\right)=0$, and $\mathrm{S}^{\prime \prime \prime}$ as the smallest solution to $\mathrm{P}\left(\mathrm{I}^{*}\left(\mathrm{~S}^{\prime \prime \prime}\right)+\mathrm{h}-\mathrm{B}^{*}\left(\mathrm{I}^{*}\left(\mathrm{~S}^{\prime \prime \prime}\right)\right)\right)=0$. These are of interest because $\Delta\left(I^{*}(S)\right)$ exceeds zero only on $\left(S^{\prime}, S^{\prime \prime \prime}\right)$ and attains its maximum at $S^{\prime \prime}$. By (1), (5) and (12), these thresholds are:

$$
\begin{array}{lll}
\mathrm{S}^{\prime} & = & 2[\overline{\mathrm{Q}}-(1+\theta \alpha) \mathrm{h}] \\
\mathrm{S}^{\prime \prime} & = & 2[\overline{\mathrm{Q}}-(1+\theta \alpha /(1+\alpha)) \mathrm{h}] \\
\mathrm{S}^{\prime \prime \prime} & = & 2[\bar{Q}+(\theta / 2-1) \mathrm{h}] .
\end{array}
$$

Similarly, we define $\tilde{\mathrm{S}}^{\prime}$ by $\tilde{\mathrm{B}}\left(\tilde{\mathrm{S}}^{\prime}\right)=0, \tilde{\mathrm{S}}^{\prime \prime}$ by $\mathrm{P}\left(\tilde{\mathrm{S}}^{\prime \prime} / 2+\mathrm{h}\right)=0$, and $\tilde{\mathrm{S}}^{\prime \prime \prime}$ by $\mathrm{P}\left(\mathrm{h}+\left(\tilde{\mathrm{S}}^{\prime \prime \prime}-\tilde{\mathrm{B}}\left(\tilde{\mathrm{S}}^{\prime \prime \prime}\right)\right) / 2\right)=0$.

These similarly define the support and maximum of $\tilde{\Delta}$. From (1) and (9), these are:

$$
\begin{array}{lll}
\tilde{\mathbf{S}}^{\prime} & = & 2[\overline{\mathbf{Q}}-(1+\theta \alpha) \mathrm{h}] \\
\tilde{\mathrm{S}}^{\prime \prime} & = & 2[\overline{\mathrm{Q}}-\mathrm{h}] \\
\tilde{\mathrm{S}}^{\prime \prime \prime} & = & 2[\bar{Q}+(\theta-1) \mathrm{h}]
\end{array}
$$

Note that $S^{\prime \prime \prime}>S^{\prime \prime}>S^{\prime}, \tilde{S}^{\prime \prime \prime}>\tilde{S}^{\prime \prime}>\tilde{S}^{\prime}, \tilde{S}^{\prime}=S^{\prime}, \tilde{S}^{\prime \prime}>S^{\prime \prime}$, and $\tilde{S}^{\prime \prime \prime}>S^{\prime \prime \prime}$. Thus, the support of $\tilde{\Delta}(\mathrm{S})$ is a right-handed extension of the support of $\Delta\left(I^{*}(S)\right)$, and $\Delta\left(I^{*}(S)\right)$ peaks to the left of than $\tilde{\Delta}(\mathrm{S})$. This is illustrated in Figure 4 , for the case $\alpha=0.8, \mathrm{~h}=0.2, \overline{\mathrm{Q}}=1$, and $\theta=1.5$.

Since $\tilde{\Delta}(\mathrm{S})=2 \Delta(\mathrm{S} / 2) \forall \mathrm{S}$, we know that $\tilde{\Delta}\left(\tilde{\mathrm{S}}^{\prime \prime}\right)=2 \Delta\left(\mathrm{I}^{*}\left(\mathrm{~S}^{\prime \prime}\right)\right)>2 \Delta\left(\mathrm{I}^{*}\left(\tilde{\mathrm{S}}^{\prime \prime}\right)\right) \geq \Delta\left(I^{*}\left(\tilde{\mathrm{S}}^{\prime \prime}\right)\right)$, and so for $S \geq \tilde{S}$ ", $\tilde{\Delta}(S)>\Delta\left(I^{*}(S)\right)$. (See Figure 4.) Thus, if the "trap" is to occur, we must have $S<\tilde{S}^{\prime \prime}$. Two questions are: First, under what conditions does the peak of $\Delta\left(I^{*}(S)\right.$ ) (which occurs at $S^{\prime \prime}$ ) poke above the $\tilde{\Delta}$ curve? And second, under what conditions does the initial portion of $\Delta\left(I^{*}(S)\right)$ (at $S^{\prime}$ ) rise more quickly than the initial portion of $\tilde{\Delta}$ ?

First, using (7), (A.1), (10), and (11) and rearranging, we find that $\Delta\left(I^{*}\left(S^{\prime \prime}\right)\right)>\tilde{\Delta}\left(S^{\prime \prime}\right)$ if 
and only if:

$$
\left(\frac{2+3 \alpha}{1+\alpha}\right)^{1+\alpha}-2(1+\alpha)-2^{\alpha}>0 .
$$

The expression on the left hand side can be verified numerically to be positive (for $\alpha \in[0,1]$ ) if and only if $\alpha<0.925316$. Thus, we have verified (i).

Second, we investigate the behaviour of the two curves near $S^{\prime}$. We know that $\Delta\left(S^{\prime}\right)=\tilde{\Delta}\left(S^{\prime}\right)=0$, and the envelope theorem readily shows us that

$$
\frac{d}{d S}[\tilde{\Delta}(S)]_{S=S^{\prime}}=\frac{d}{d S}\left[\Delta\left(I^{*}(S)\right)\right]_{S=S^{\prime}}=0
$$

Thus, in a (right-handed) neighborhood of $S^{\prime}$, the curve that dominates is the one with the greatest second derivative. It is mechanical to verify:

$$
\begin{aligned}
& 2(1+\alpha) \frac{d^{2}}{d S^{2}}[\tilde{\Delta}(S)]_{S=S^{\prime}} \\
& =\frac{(1+\alpha)}{\left(I^{*^{\prime}}(S)\right)^{2}} \frac{d^{2}}{d S^{2}}\left[\Delta\left(I^{*}(S)\right)\right]_{S=S^{\prime}} \\
& =-P^{\prime \prime}\left(\frac{S^{\prime}}{2}+h\right) \theta h-P^{\prime}\left(\frac{S^{\prime}}{2}+h\right) .
\end{aligned}
$$

From (12), this means that $\Delta\left(I^{*}\right)$ is more convex than $\tilde{\Delta}$ at $S^{\prime}$ if and only if

$$
\frac{2(1+\alpha)^{2}}{(1+2 \alpha)^{2}}>1
$$

or 


$$
\alpha<\frac{1}{\sqrt{2}} \text {. }
$$

This, then, gives us (ii).

There is, finally, a simple relationship between the two types of regime choice failure. Since we know that $\tilde{\Delta}(S)>\Delta(S / 2)$ always holds (where the function is positive), if $\Delta\left(I^{*}(S)\right)>\tilde{\Delta}(S)$, then $\Delta\left(I^{*}(S)\right)>\tilde{\Delta}(S)>\Delta(S / 2)$. Therefore, if $K$ is such that the government can get trapped into providing supports, a drop in $\mathrm{K}$ will put it into the range where the government can get stuck in neutral. This is (iii). This inequality further shows that whenever the government can get trapped into providing supports, necessarily both policy regimes are equilibria: "traps" and "bubbles" go together. This is (iv). This completes the derivation of Proposition 6. 


\section{Bibliography.}

Anderson, Ronald W. and Christopher L. Gilbert (1988). "Commodity Agreements and Commodity Markets: Lessons from Tin." Economic Journal 98:389 (March), pp. 1-15.

Atkinson, A. B. (1970). "On the Measurement of Inequality," Journal of Economic Theory 2:3 (September), pp. 244-63.

Babcock, Bruce A., Colin A. Carter and Andrew Schmitz (1990). The Political Economy of U.S. Wheat Legislation." Economic Inquiry, XXVIII:2 (April), pp. 335-53.

Baldwin, Robert, E. (1982). "The Political Economy of Protectionism," in Jagdish N. Bhagwati, Import Competition and Response, Chicago: University of Chicago Press.

Blanchard, Olivier (1979), "Speculative Bubbles, Crashes and Rational Expectations," Economic Letters 3, pp. 387-9.

Carr, Barry, Klaus Frohberg, Hartley Furtan, S.R. Johnson, William H. Meyers, Tim Phipps, and G.E. Rossmiller (1988). "A North American Perspective on Decoupling." In Miner, William M. and Dale E. Hathaway (ed.), World Agricultural Trade: Building a Consensus. Halifax, Nova Scotia: Institute for Research on Public Policy and Institute for International Economics.

Deaton, A.S. and Guy Laroque (1992). "On the Behaviour of Commodity Prices," Review of Economic Studies 59:1 (January), pp. 1-24.

Diba, Behzad T. and Herschel I. Grossman (1988). "The Theory of Rational Bubbles in Stock Prices," Economic Journal 98:392 (September), pp. 746-54.

Eaton, Jonathan, and Gene M. Grossman (1985). "Tariffs as Insurance: Optimal Commercial Policy when Domestic Markets are Incomplete," Canadian Journal of Economics 18 (May), pp. 258-72.

Fisher, Bart S. (1972). The International Coffee Agreement: A Study in Coffee Diplomacy. New York: Praeger Publishers.

Finlayson, Jock A. and Mark W. Zacher (1988). Managing International Markets. New York: Columbia University Press.

Fox, William (1974). Tin: The Working of a Commodity Agreement. London: Mining Journal Books Limited.

Gardner, Bruce L. (1983). "Efficient Redistribution through Commodity Markets," American Journal of Agricultural Economics 65:2 (May), pp. 225-34. 
(1987). "Causes of U.S. Farm Commodity Programs," Journal of Political Economy 95:2, pp. 290-310.

(1992). "Changing Economic Perspectives on the Farm Problem," Journal of Economic Literature XXX:1 (March), pp. 62-101.

Gibson-Jarvie, Robert (1986). The Tin Crisis: A Woodhead-Faulkner Special Report. Cambridge: Woodhead-Faulkner.

Gilbert, Christopher L. (1987). "International Commodity Agreements: Design and Performance," World Development, 15:5, May 1987, pp. 591-616.

Greenstone, W. D. (1981). "The Coffee Cartel: Manipulation in the Public Interest." Journal of Futures markets 1:1, pp. 3-16.

Halow, Joseph (1989). U. S. Grain: The Political Commodity. Lanham, MD: University Press of America. Ch. V: "Continued Agricultural Short-Sightedness."

Hart, O.D., and D.M. Kreps (1986). "Price Destabilizing Speculation," Journal of Political Economy, 94, 927-52.

Johnson, D. Gale (1973). World agriculture in disarray. London, Macmillan; New York, St. Martin's Press for the Trade Policy Research Centre.

Krasner, Stephen D. (1973). "Manipulating International Coffee Markets: Brazilian Coffee Policy 1902 to 1962," Public Policy 21:4, pp. 279-85.

Krueger, Anne O. (1974). "The Political Economy of the Rent-Seeking Society," American Economic Review 74 (June), pp. 291-303.

Kydland, F. and E. C. Prescott (1977). "Rules Rather than Discretion: The Inconsistency of Optimal Plans," Journal of Political Economy, 85:3, pp. 513-48.

McLaren (1992). "Speculative Equilibria of 'Managed' Primary Commodity Markets," Columbia University Department of Economics Discussion Paper, September. (1993) "Commodity-Price-Destabilizing Commodity Price Stabilization," Columbia University Department of Economics Discussion Paper, July.

Miranda, Mario J. and Peter G. Helmberger (1988). "The Effects of Commodity Price Stabilization Programs," American Economic Review 78:1 (March), pp. 46-58.

Nappi, Carmine (1979). Commodity Market Controls. Lexington Books, Lexington, Mass.

Newbery, D.M.G., and J.E. Stiglitz, (1981). The Theory of Commodity Price Stabilization: a Study 
in the Economics of Risk. Oxford: Oxford University Press.

Obstfeld, Maurice (1986). "Rational and Self-Fulfilling Balance-of-Payments Crises," American Economic Review, 76:1, pp. 72-81.

Peltzman, Sam (1976). "Toward a More General Theory of Regulation," Journal of Law and Economics, 19 (August), pp. 211-40.

Posner, Richard A. (1975). "The Social Costs of Monopoly and Regulation," Journal of Political Economy 83:4 (August), pp. 807-27.

Salant, Stephen (1983). "The Vulnerability of Price Stabilization Schemes to Speculative Attack," Journal of Political Economy, 91, 1-38.

Short, Joseph (1987). American Business and Foreign Policy: Cases in Coffee and Cocoa Trade Regulation 1961-1974. Garland Publishing, New York.

Williams, Jeffrey and Brian Wright (1991). Storage and Commodity Markets. Cambridge: Cambridge University Press.

Wright, Brian and Jeffrey Williams (1984). "Anti-Hoarding Laws: A Stock Condemnation Revisited," American Journal of Agricultural Economics 66:4 (November), pp. 447-55. 


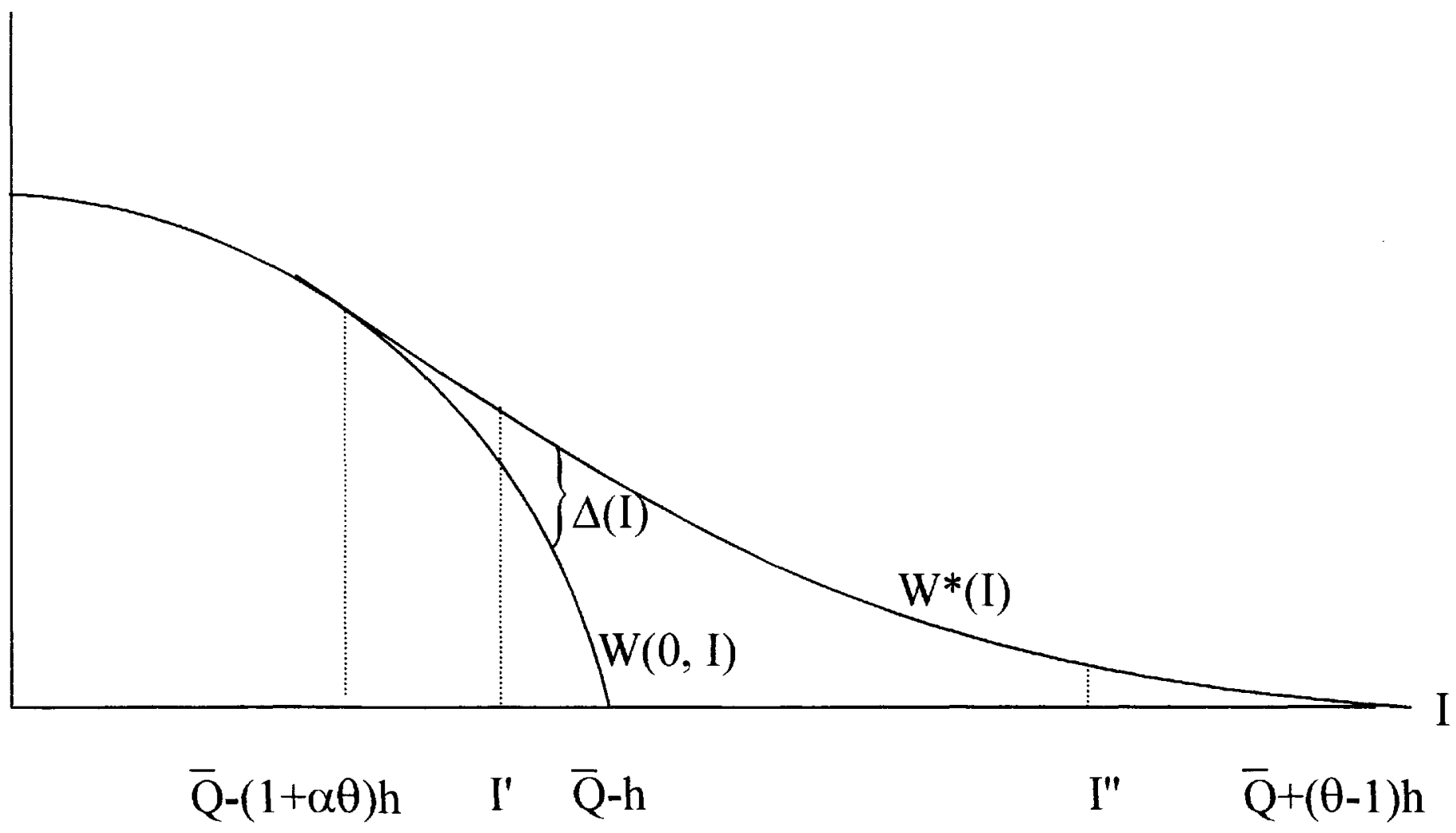

Figure 1. 


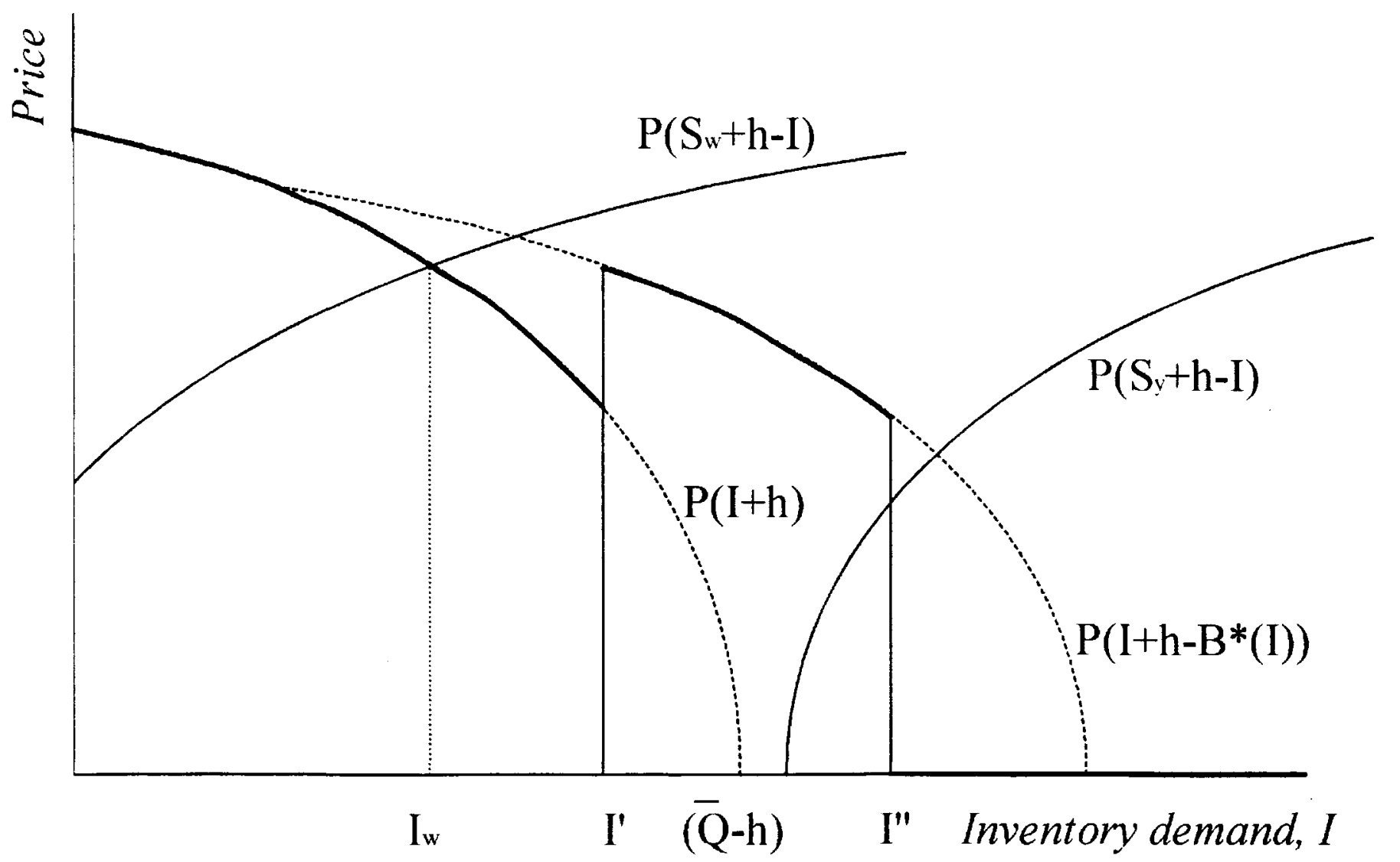

Figure 2(a).

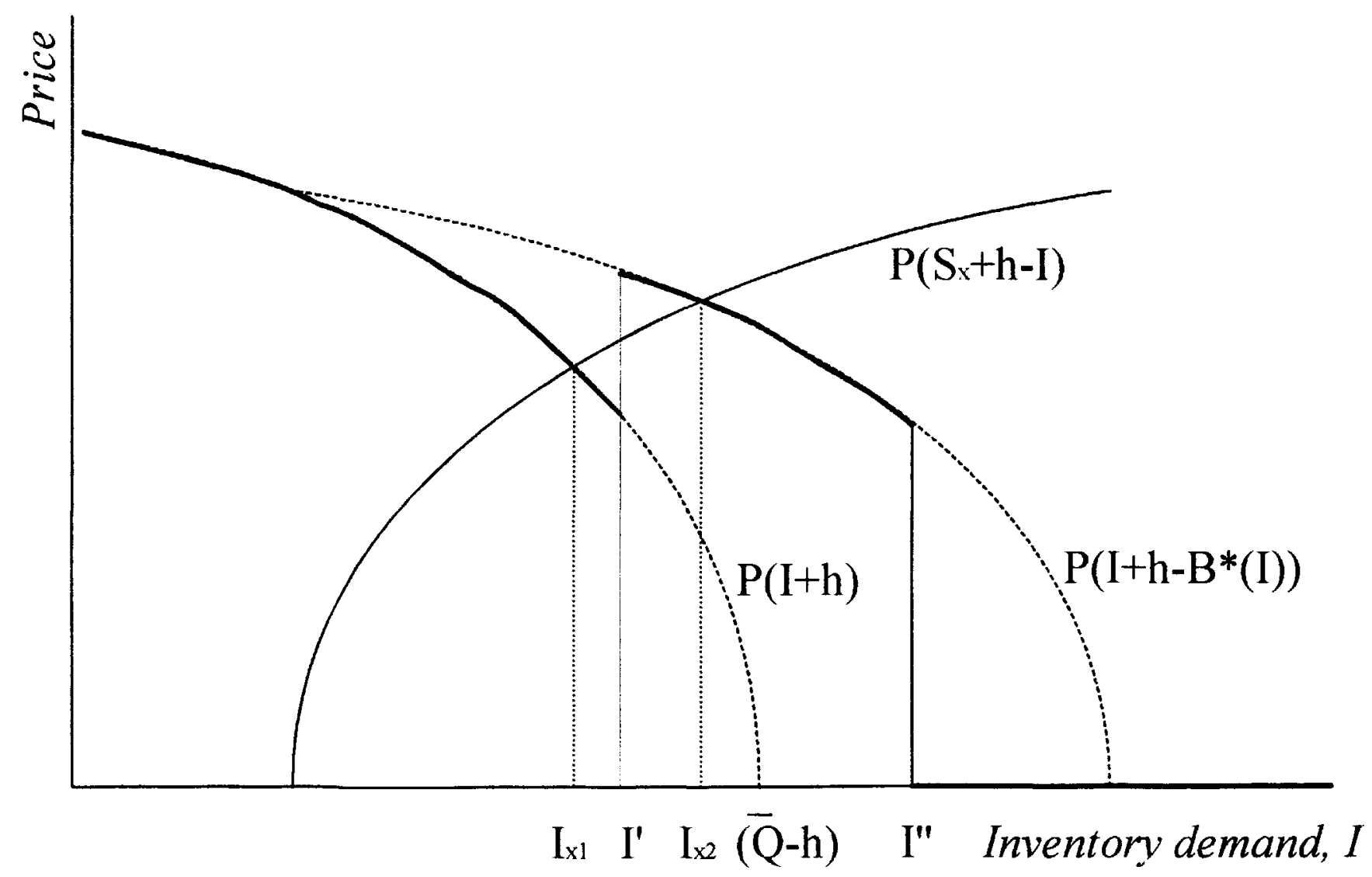

Figure 2(b). 


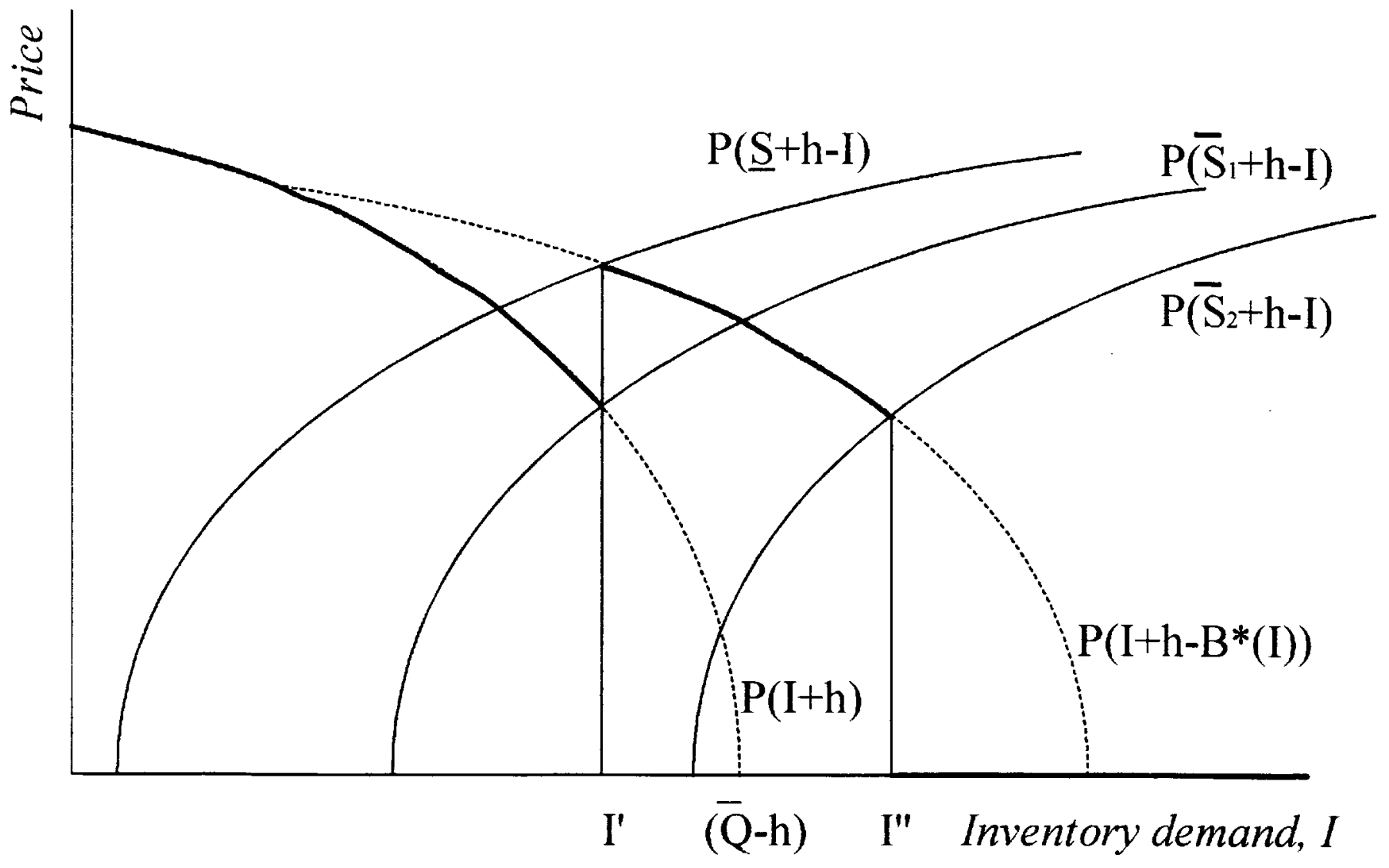

Figure 3. 


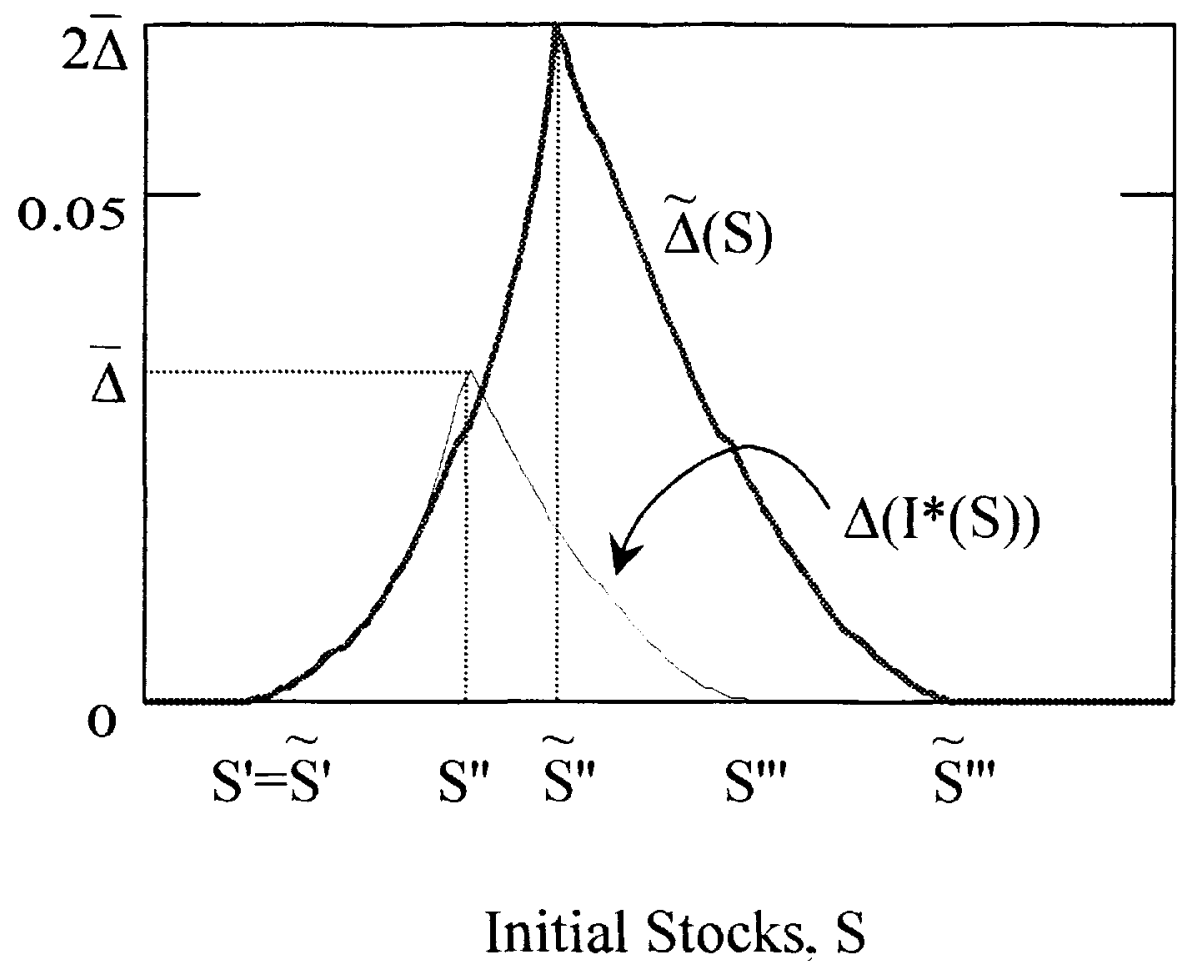

Figure 4. 


\section{4-1995 Discussion Paper Series \\ Department of Economics \\ Columbia University \\ 420 W. 118 St., Room 1022 \\ New York, N.Y., 10027}

The following papers are published in the 1994-95 Columbia University Discussion Paper series which runs from early November to October 31 (Academic Year). Domestic orders for discussion papers are available for purchase at $\$ 8.00$ (US) each and $\$ 140.00$ (US) for the series. Foreign orders cost $\$ 10.00$ (US) for individual paper and $\$ 185.00$ for the series. To order discussion papers, please send your check or money order payable to Department of Economics, Columbia University to the above address. Be sure to include the series number for the paper when you place an order.

708. Trade and Wages: Choosing among Alternative Explanations Jagdish Bhagwati

709. Dynamics of Canadian Welfare Participation

Garrey F. Barret, Michael I. Cragg

710. Much Ado About Nothing? Capital Market Reaction to Changes in Antitrust Precedent concerning Exclusive Territories.

Sherry A. Glied, Randall S. Kroszner

711. The Cost of Diabetes

Matthew Kahn

712. Evidence on Unobserved Polluter Abatement Effort

Matthew E. Kahn

713. The Premium for Skills: Evidence from Mexico

Michael Cragg

714. Measuring the Incentive to be Homeless

Michael Cragg Mario Epelaum

715. The WTO: What Next?

Jagdish Bhagwati

716. Do Converters Facilitate the Transition to a New Compatible Technology?

A Dynamic Analysis of Converters

Jay Phil Choi 
1994-95 Discussion Paper Series

717. Wealth Effects, Distribution and The Theory of Organization Patrick Legros, Cornell University -Andrew F. Newman, Columbia University

718. Trade and the Environment: Does Environmental Diversity Detract from the Case for Free Trade?

-Jagdish Bhagwati and T.N. Srinivasan (Yale Univ)

719. US Trade Policy: Successes and Failures

-Jagdish Bhagwati

720. Distribution of the Disinflation of Prices in 1990-91 Compared with Previous Business Cycles -Philip Cagan

721. Consequences of Discretion in hte Formation of Commodities Policy -John McLaren 